\title{
Combined Membrane and Thermal Desalination Processes for the Treatment of Ion Exchange Resins Spent Brine
}

\author{
M. Micari ${ }^{1 *}$, A. Cipollina ${ }^{2}$, A. Tamburini ${ }^{2 *}$, M. Moser ${ }^{1}$, V. Bertsch ${ }^{1}$, G. Micale $^{2}$ \\ 1 German Aerospace Center (DLR), Institute of Engineering Thermodynamics, \\ Pfaffenwaldring 38-40, 70569 Stuttgart, Germany \\ 2 Dipartimento di Ingegneria (DI), Università degli Studi di Palermo (UNIPA), viale delle \\ Scienze Ed. 6, 90128 Palermo, Italy \\ *corresponding authors. E-mail: marina.micari@dlr.de; alessandro.tamburini@unipa.it
}

\begin{abstract}
The disposal of industrial wastewater effluents represents a critical environmental issue. This work focuses on the treatment of the spent brine produced by the regeneration of ion exchange resins employed for water softening. For the first time, a comprehensive techno-economic assessment and an analysis of the energy requirements of the treatment chain are carried out, via the simulation of ad hoc implemented models. The chain is composed of nanofiltration, double-stage crystallization and multi-effect distillation. The valuable product is the brine produced by the multi-effect distillation, which can be re-used for the regeneration. Therefore, the treatment chain's economic feasibility is evaluated via the Levelized Brine Cost, which includes the terms of cost and revenue of every unit in the chain. Varying the nanofiltration recovery, the treatment system always turns out to be economically competitive, since the Levelized Brine Cost is lower than the current cost of the fresh regenerant solution $\left(8 \$ / \mathrm{m}^{3}\right)$. In particular, the lowest value of $4.9 \$ / \mathrm{m}^{3}$ is found for a nanofiltration recovery of $25 \%$. Moreover, the cost of the reactant used in the crystallization and the revenues of $\mathrm{Mg}(\mathrm{OH})_{2}$ and $\mathrm{Ca}(\mathrm{OH})_{2}$ play a prominent role in all scenarios. Regarding the energy demand, the thermal energy required by the evaporator is the main contribution and covers more than $30 \%$ of the operating costs (excluding the cost of the crystallization reactant, which is balanced by the hydroxides revenues). Therefore, the costs can be significantly reduced when waste heat is available in the industrial site. Overall, the treatment chain is economically feasible and allows reducing the industrial environmental impact by recycling waste streams and waste heat.
\end{abstract}

\section{KEYWORDS}

Industrial Wastewater; Nanofiltration; Wastewater Treatment; Techno-economic analysis; Circular Economy; Waste heat recovery 


\section{INTRODUCTION}

The increasing environmental pollution along with the growing demand for energy and raw materials is leading to the need of a more sustainable development. With this respect, one of the most important requirements to fulfil, consists in saving water and energy simultaneously [1]. The consumption of water and energy has significantly increased in the past years and their applications are often interconnected and mutually reinforcing [2]. Water is used in power plants and energy is fundamental for fresh water production and water treatment processes [3]. The concept of the 'water-energy nexus' describes all the interdependencies and the dynamic linkages between water and energy [4]. This topic has drawn more and more attention in recent years and it may constitute the basis of future energy and water planning. The water-energy nexus has been investigated from several different angles and on different scales. Comprehensive studies were carried out from the 'water for energy' as well as the 'energy for water' perspective. Regarding the first one, water is widely needed in the energy sector, such as in the fuel production and in the hydropower generation [5-8]. For what concerns the 'energy for water' perspective, water systems are among the major consumers of energy resources [9]. The energy requirement depends on the water quality and on the process involved [10]. Wastewater treatment is a very electricity-intensive process and the energy consumption cost was found to cover up to $40 \%$ of the overall municipal wastewater treatment plants' operating costs [11]. Therefore, increasing the plants' energy efficiency may lead to a net reduction of the expenses [12]. The optimization of the energy efficiency and the identification of the energy inefficiencies in the wastewater treatment plants are very popular topics in literature [13], [14]. Many strategies to optimize the energy efficiency are focused on the energy recovery within the wastewater treatment plants, which may be realized in self-sufficient plants [15] or via networks containing industrial processes using water, wastewater treatment units and recovery heat exchangers [16]. In general, the exploitation of the thermal energy stored in the water streams circulating in the network, through the development of a suitable flowsheet and the design of heat exchangers, allows a net reduction of the total energy requirement [17]. Overall, the investigation of the energy efficiency of wastewater treatment plants has mostly focused on municipal wastewater, although some studies evaluated also the energy performances of drinking water treatment plants, applying the energy benchmarks defined for the wastewater treatment plants [18].

However, nowadays, a rising attention is devoted to the treatment of industrial wastewater effluents. Therefore, a smart treatment of industrial effluents may represent a double advantage: (i) it would reduce the amount of wastes injected into the environment and (ii) it would make 
the effluents a new source of raw materials. In this context, several industrial effluents can be considered [19]: among others, brines produced in desalination plants or effluents deriving from the textile industry. Different ways to manage the desalination brines were investigated and implemented, such as brine minimization via thermal- or membrane-based technologies, direct re-use or extraction of minerals and salts for other applications [20], [21]. In many cases, especially when organic compounds have to be removed, energy consumption may be a major issue. The same can be said for the treatment of textile wastewaters, which represent a very critical issue for the environment, because of the high volumes produced and because of their high content of organic pollutants (due to the dyes used in the industrial textile processes). For this reason, the contaminated textile wastewaters are typically treated via membrane processes [22] or via advanced oxidation processes [23], with the purpose of recycling the treated brine to the following dyeing operation.

Another industrial brine which has been taken into consideration is the one produced during the regeneration of Ion Exchange resins (IEXs), which are employed for a wide range of applications. Usually, the regeneration of the resins is carried out by using a regenerant solution at a certain concentration and the spent regenerant composition depends on the resins application. For example, IEXs are commonly used for water purification purposes, to remove perchlorates or nitrates from groundwater. The removal of these pollutants, for instance via catalytic reduction technology [24] or via biological treatment makes the re-use of the treated brine in the IEX regeneration viable and allows the reduction of the amount of fresh salt-water (regenerant) solution to be employed.

The IEX resins are also commonly used for water softening. In this case, the spent IEX resins are rich of the hardness (the ions $\mathrm{Mg}^{2+}$ and $\mathrm{Ca}^{2+}$ ) removed from the softened water and the solution employed for the regeneration is a NaCl-water solution. Thus, the waste effluent arising from the regeneration of the spent resins is a water solution rich of sodium, chloride, magnesium and calcium ions. The discharge of the spent regenerant solution may cause serious environmental issues, especially because of the large volumes produced. A few studies in literature investigated alternative methods for the regeneration of the resins and strategies for the brine recycling. Flodman and Dvorak proposed brine reclaim operations or strategies to reduce salt consumption during regeneration [25]. They found that brine recycling systems, consisting of a single or a double tank where the spent brine effluent was partially recycled, allowed reducing the salt consumption and discharge without an increase of hardness leakage, but with a reduction of the removal efficiency. Hu et al. proposed a novel method to purify desalinated seawater instead of the conventional two-bed ion exchange. This process, called 
Chemical-Free Ion Exchange (CFIE), consisted of a mixed bed with strong acid and weak basic resins and an anion bed [26]. Other methods include the employment of thermally regenerable resins, whose capacity of removing salts from solutions by sorption depends on the temperature [27] and the introduction of other cation exchange forms, for example resins charged with $\mathrm{Al}^{3+}$ or with $\mathrm{K}^{+}$[28], [29]. Regarding the recycling strategies, Chen et al. proposed a closed-loop consisting of a bipolar membrane electrodialysis stack and a crystallizer, to restore the acid and the basic solutions used for the regeneration of weak resins and to recover the hardness minerals [30]. For most of these novel regeneration processes, the economic feasibility is not assessed, while it may constitute a crucial point.

This work proposes a recycling strategy for the spent regenerant solution of strong resins employed for water softening and presents, for the first time, a detailed and comprehensive techno-economic and energetic analysis of the whole treatment chain. The chain was developed within the framework of the EU-funded project Zero Brine [31], whose aim is to introduce new solutions to treat different types of industrial brines, promoting a circular economy approach at industrial scale. In particular, this work deals with the treatment of the industrial brine produced by the water softening plant, owned by the water industry Evides, in Rotterdam, The Netherlands. Currently, a fresh regenerant solution is continuously supplied to the resins and the effluent is disposed into the sea, without a treatment process. On the contrary, the system analysed in this work presents a treatment chain, which is depicted in Figure 1. It consists of a Nanofiltration (NF) stage to concentrate the bivalent cations in the retentate, which is then fed to a double crystallization stage to produce $\mathrm{Mg}(\mathrm{OH})_{2}$ and $\mathrm{Ca}(\mathrm{OH})_{2}$ crystals. Conversely, the permeate of the NF stage, together with the effluent of the crystallization, is sent to a MultiEffect Distillation (MED) stage, where the $\mathrm{NaCl}$ concentration reaches the one required for the IEX regeneration process. For each stage, we developed a detailed techno-economic model and then, we connected the models via mass balances to simulate the treatment chain. The proposed approach allows (i) a net decrease of the salt and water consumption, (ii) the reduction of the environmental impact of the industrial process and the amount of produced waste and (iii) the re-utilization of waste materials and waste heat. The case study was already presented in a previous work by the same authors [57]. There, only the MED unit was investigated in detail in order to identify the most suitable operating conditions in presence of different steam qualities and costs. 


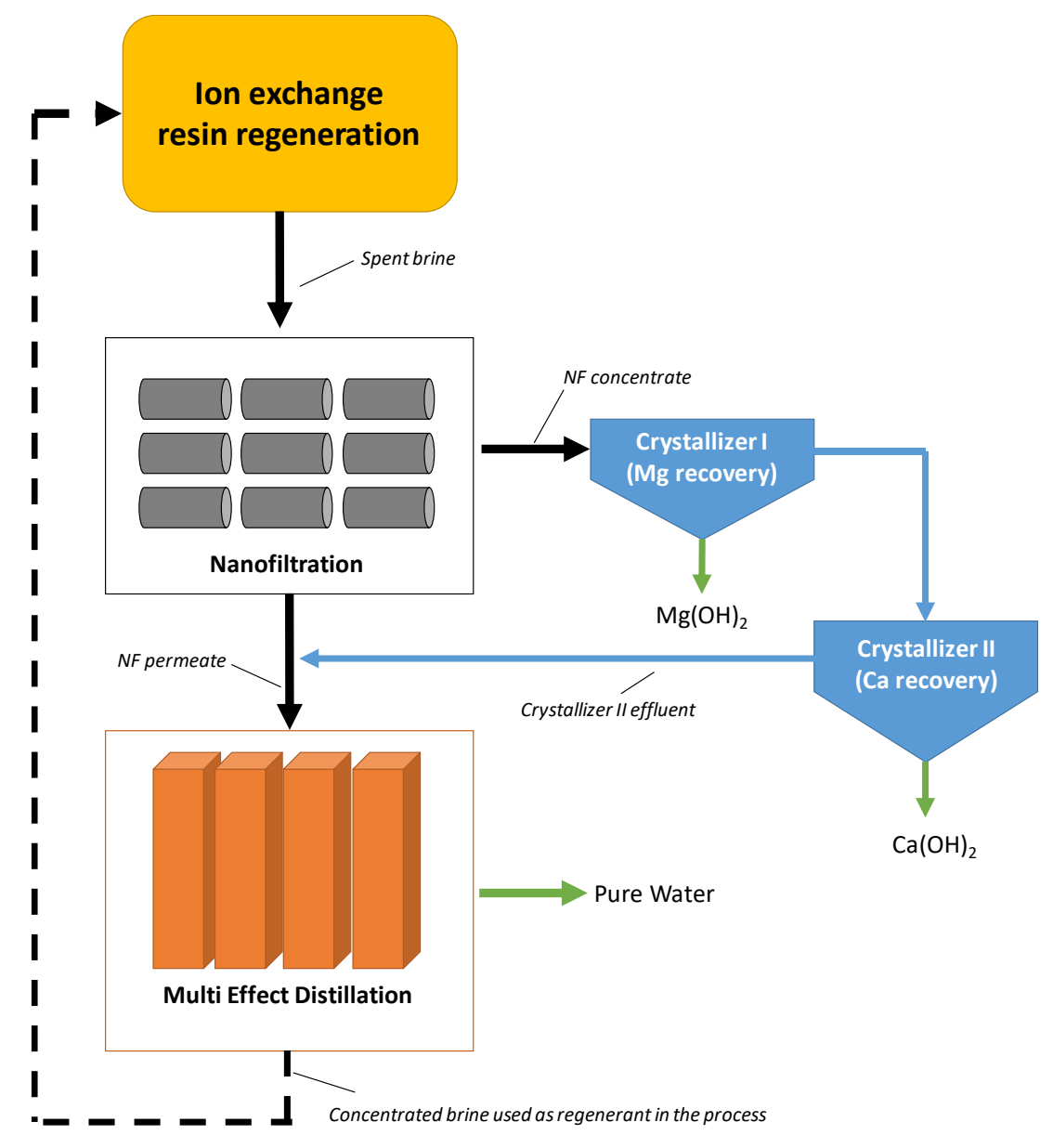

Figure 1. Schematic representation of the treatment chain for the wastewater effluent produced by the regeneration of IEX resins employed in a water softening plant.

This work presents the whole treatment chain as an 'energy for water' system and reports the energy demand of the single units, since this may constitute a crucial point for industrial wastewater treatment and its estimation is very much dependent on the effluent under investigation. We therefore make reference to a real case study and the properties of the effluent to be treated, such as composition and flow rate, are defined on the basis of the real wastewater effluent generated by the Evides water softening plant. The technical design of the plant is always performed with reference to a full-scale, where the whole amount of effluent produced by IEX regeneration is processed in the treatment chain. Concerning the economic analysis, the contributions of the single units are highlighted in terms of costs and revenues given by the byproducts. The economic feasibility of the chain is defined via the introduction of the global Levelized Brine Cost (LBC), which represents the cost that the concentrate brine would have at the break-even point (see equation 6 in section 3). This performance parameter includes for the first time all the terms of cost of the treatment chain and it is meant to be compared with the cost of the fresh regenerant $\mathrm{NaCl}$-water solution, currently employed for the resins regeneration, 
to evaluate the competitiveness of the proposed technology. The results reported in this work concern the impact of some operating conditions, in particular the nanofiltration recovery and the inlet feed flow rate, on the global economic feasibility, to identify the most suitable operating conditions and the most energy-intensive and cost-intensive units in the treatment chain. Overall, this work focuses on the global treatment plant design and on the estimation of the energy requirements for the real case study, with the aim of enhancing the sustainability of the industrial process producing the effluent.

\section{MODELS}

The treatment chain shown in Figure 1 presents a NF stage, coupled with a double-stage crystallizer and a MED unit. For each unit, a technical model was implemented and coupled with an economic tool for the estimation of the capital and the operating costs. Then, the models were interconnected via suitable mass-balances to simulate the treatment chain. Table 1 shows the main inputs and outputs of the three models: different colours and marks are used in the table to show how the models are interconnected for the simulation of the treatment chain. In the real chain, the output retentate produced by the NF unit constitutes the feed solution of the crystallizer (the relevant input of the crystallizer model and output of the NF model are written in blue, index (ii)), while the solution resulting from the mixing of the nanofiltration permeate and the crystallizer effluent (see Figure 1) is the feed solution of the MED unit (the relevant input of the MED model and outputs of the NF and the crystallizer models are written in red, index (i)).

Table 1. Main inputs and outputs of the single models and interconnections in the treatment chain. 


\begin{tabular}{|c|c|c|c|}
\hline & Nanofiltration & Crystallizer & $\begin{array}{l}\text { Multi-Effect } \\
\text { Distillation }\end{array}$ \\
\hline \multirow{4}{*}{$\frac{n}{2}$} & Feed flow rate & (ii) -> Inlet flow rate & (i) -> Inlet flow rate \\
\hline & Ions concentration & $\begin{array}{c}\text { (ii) -> Concentration of } \\
\mathrm{Mg}^{2+}\end{array}$ & $\begin{array}{l}\text { (i) }->\text { Inlet } \mathrm{NaCl} \\
\text { concentration }\end{array}$ \\
\hline & Feed pressure & $\begin{array}{c}\text { (ii) }->\text { Concentration of } \\
\mathrm{Ca}^{2+}\end{array}$ & $\begin{array}{l}\text { Required brine } \\
\text { composition }\end{array}$ \\
\hline & Plant Recovery & $\begin{array}{c}\text { Concentration of the alkaline } \\
\text { solution }(\mathrm{NaOH})\end{array}$ & Steam temperature \\
\hline \multirow{6}{*}{ 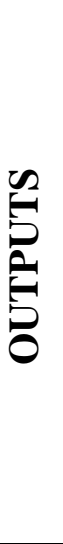 } & Ions rejection & Alkaline solution flow rate & Heat exchanger area \\
\hline & Water flux & Flow rate of $\mathrm{Mg}(\mathrm{OH})_{2}$ & Preheater area \\
\hline & Plant size & Flow rate of $\mathrm{Ca}(\mathrm{OH})_{2}$ & End condenser area \\
\hline & $\begin{array}{l}\text { Permeate flow rate and } \\
\text { composition }->\text { (i) }\end{array}$ & Effluent flow rate -> (i) & $\begin{array}{l}\text { Cooling water flow } \\
\text { rate }\end{array}$ \\
\hline & $\begin{array}{c}\text { Retentate flow rate } \\
\text { and composition -> (ii) }\end{array}$ & Effluent composition -> (i) & Steam flow rate \\
\hline & $\begin{array}{c}\text { Electric energy } \\
\text { requirement }\end{array}$ & Electric energy requirement & $\begin{array}{l}\text { Electric and thermal } \\
\text { energy requirements }\end{array}$ \\
\hline
\end{tabular}

The main modelling activity reported in this work concerns the NF process, whose implementation at different scales is described in section 2.1 and in the Appendix A. Crystallizers are simulated through the implementation of mass balances, to evaluate the flow rates of the required alkaline solution and the produced hydroxides. The model adopted for the MED unit is extensively described elsewhere [57] and it is not reported here for brevity. The MED operating conditions which resulted to be the best performing [57] are employed for the simulation of the treatment chain. In the following, a short description of the developed models is reported.

\subsection{Nanofiltration}

\subsubsection{Technical model}

The NF model is developed on different scales, i.e. the lowest scale describes the mechanisms within the membranes; the middle-scale is relevant to a single NF element; the high scale regards the whole NF plant, given by a certain amount of vessels arranged in parallel, each one containing some NF elements in series. The schematic representation of the NF plant, as it is described in the multiscale model, is reported in Figure 2. 


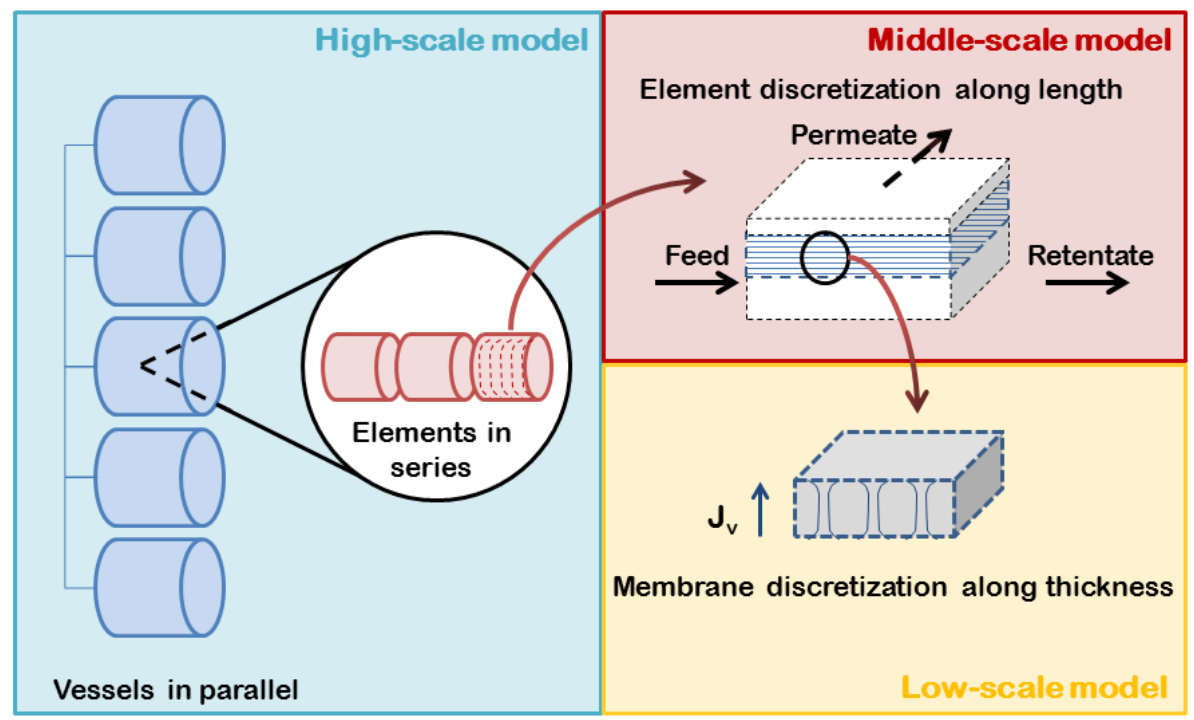

Figure 2. Different scales of modelling of the nanofiltration unit.

The detailed description of the multi-scale model, including the equations employed for the low-scale and the middle-scale model and the description of the iterative procedures is reported in the Appendix A. For what concerns the low-scale model, the mechanisms within the membranes are described via the Donnan Steric Pore Model with Dielectric Exclusion (DSPM$\mathrm{DE})$. In literature, there are numerous studies regarding the modelling approaches of NF membranes and the DSPM-DE model is the most widely used [32], [33], [53], [61]. The model allows a full characterization of the NF membrane, knowing four parameters, i.e. the membrane pore radius ( $\mathrm{r}_{\text {pore }}$ ), the active layer membrane thickness $\left(\delta_{\mathrm{m}}\right)$, the dielectric constant within the pores $\left(\varepsilon_{\text {pore }}\right)$ and the fixed charge density $\left(\mathrm{X}_{\mathrm{d}}\right)$. These parameters are needed to estimate the membrane rejection of a species $i$, defined below.

$$
R_{i}=1-\frac{C^{p}{ }_{i}}{C^{\text {feed }}}
$$

where $\mathrm{C}^{\mathrm{p}}{ }_{\mathrm{i}}$ is the concentration of the species $i$ in the permeate solution and $\mathrm{C}^{\mathrm{feed}}{ }_{\mathrm{i}}$ is the concentration of the species $i$ in the feed.

The DSPME-DE model derives from the resolution of the extended Nernst-Plank equation along the thickness of the membrane, which takes into account the three different mechanisms of ion transport, i.e. convection, diffusion and electro-migration, as shown in Figure 3. Along the y axis, which corresponds to the thickness of the membrane, the membrane is discretized in a certain number of elements, taken equal to 50 in the present work on the basis of a preliminary sensitivity analysis (see Appendix A.4). The index employed for the elements along the y axis is ' $j$ ', while the index ' $i$ ' represents the different ionic species, as typically used in literature. 


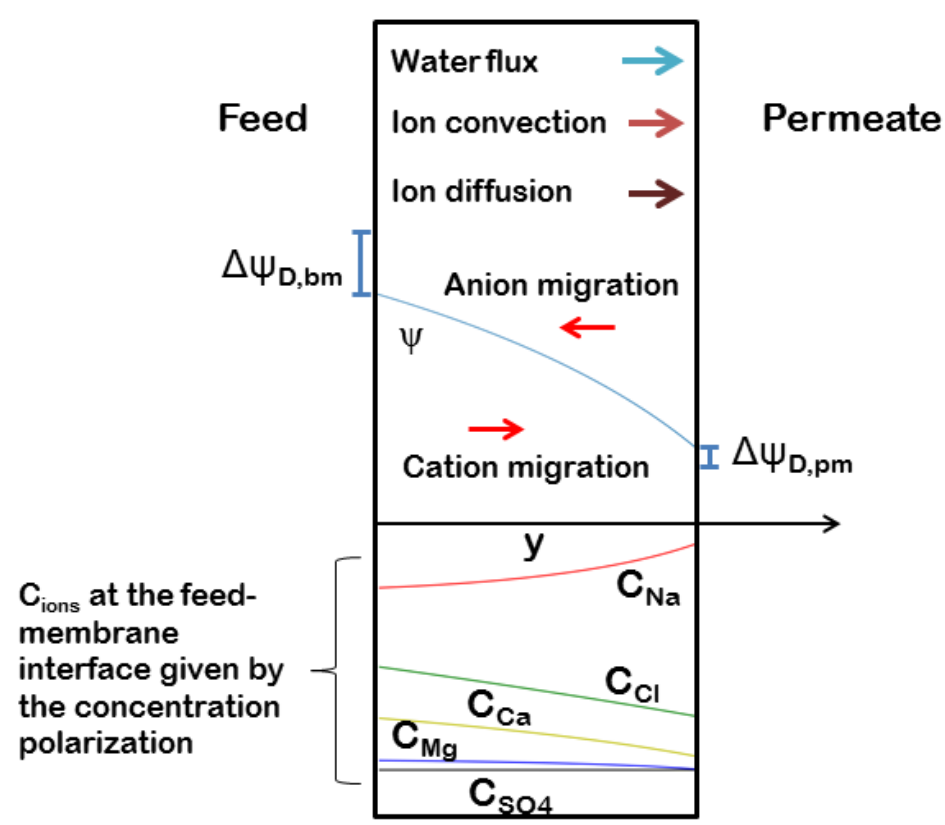

Figure 3. Profiles of electric potential and ions' concentration through the membrane and relevant fluxes.

At the middle scale, the membrane model is integrated for the resolution of a whole NF membrane element. A schematic representation of the NF element, as described in the model, is reported in Figure 4. The membrane length, along the main feed flow direction, is discretized and mass balances are applied to each discretization interval. Note that a one-dimensional model can be applied to a spiral wound element without significant errors, as shown by Roy et al. [62], since the variation of the permeate concentration and flow rates along the width of the membrane is negligible.

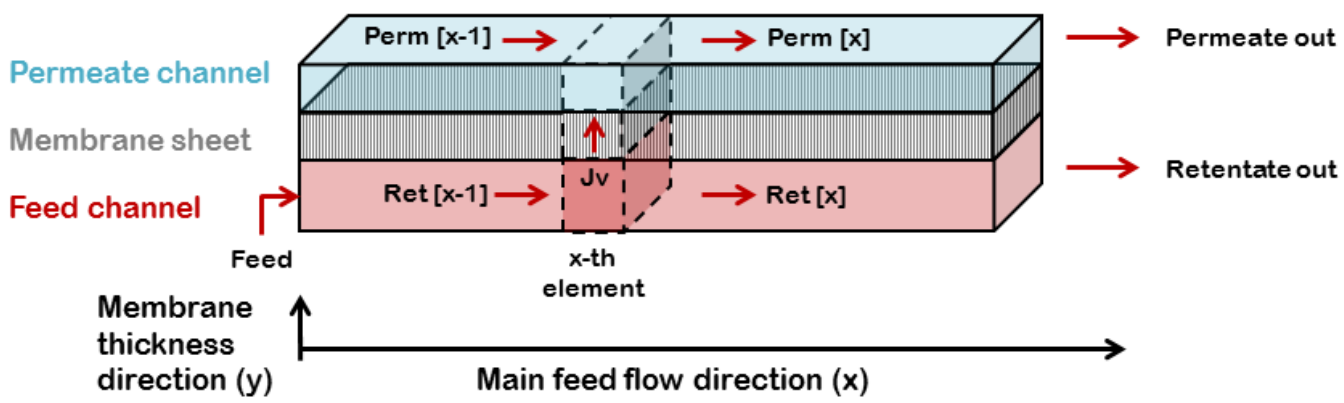

Figure 4. Schematic representation of an unwound spiral-wound NF membrane element.

Typically, in spiral-wound elements, a certain number of membrane leaves are wounded together in a parallel arrangement [34]. The spiral-wound elements are placed in series within a pressure vessel, where the concentrate flow rate produced by one element is fed to the 
following one, while the produced permeates are mixed together. In analogy with high-scale plants described in literature, each pressure vessel includes 6 elements, each one composed of 5 membrane leaves wounded together. The total membrane area exposed by each pressure vessel is equal to $30 \mathrm{~m}^{2}$ [38]. Also, according to the recovery rate to be achieved $\left(\mathrm{M}_{\mathrm{p}, \text { out }} / \mathrm{M}_{\text {feed, }}\right.$, which corresponds to a required permeate flow rate), several vessels are typically arranged in parallel in order to increase the available membrane area [38].

The high-scale model deals with the design of the whole NF plant and the estimation of the required number of pressure vessels arranged in parallel (see Figure 2). A schematic representation of the arrangement of the NF plant is reported in Figure 5.

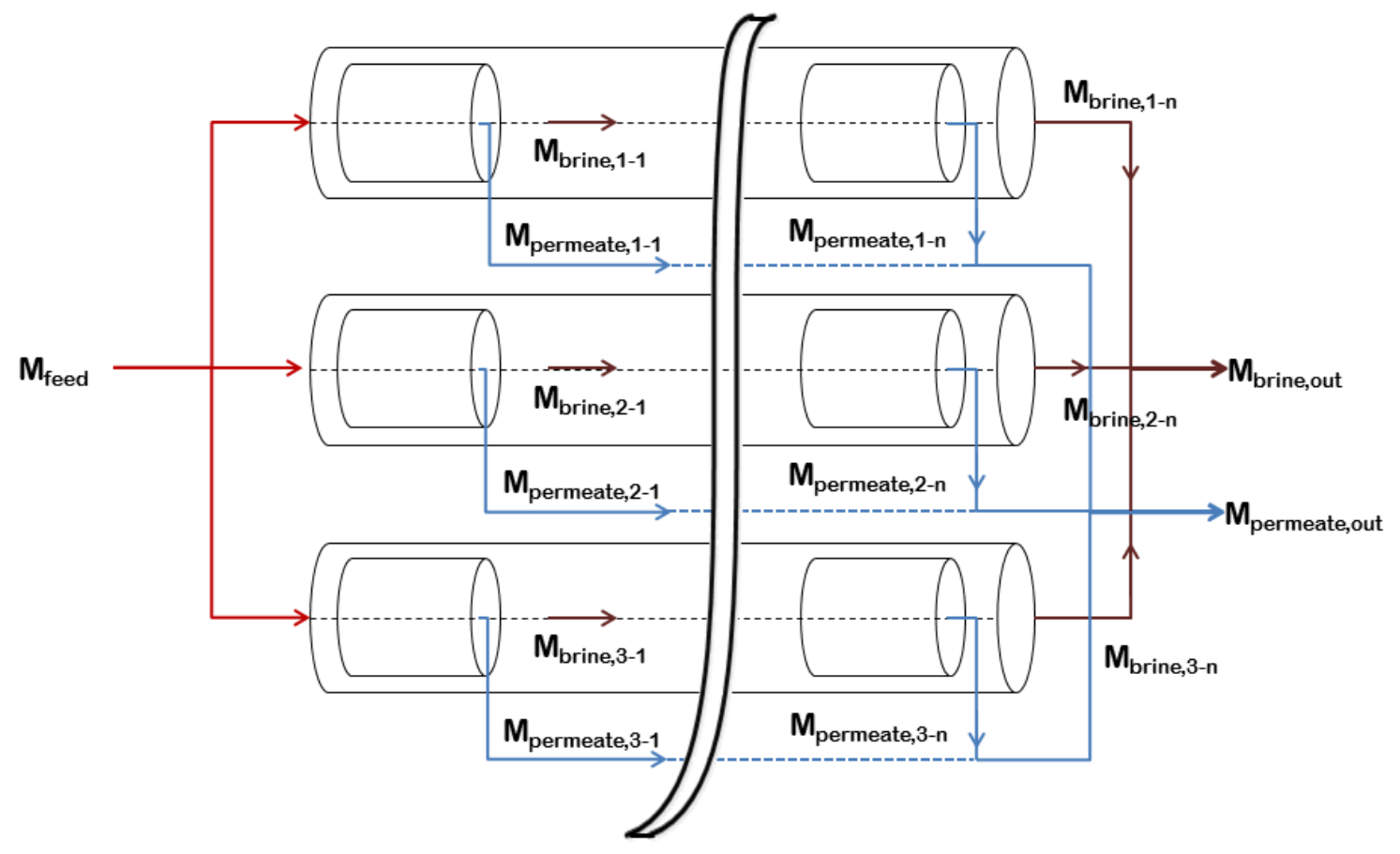

Figure 5. Schematic representation of the arrangement of the pressure vessels in parallel in the NF plant.

\subsubsection{Economic model}

Regarding the economic model, the Verberne cost model is employed [35], [37], [38]. All the equations of the model are based on practical data provided by NF units suppliers and its first applications were related to treatment systems for the removal of pesticides, hardness and nitrate from soil water [38]. The number of vessels, the feed flow rate and the operating feed pressure are the required inputs. The equations used for the calculation of the capital costs are reported in Table 2.

Table 2. Capital cost estimation for the NF plant [38]. 


\begin{tabular}{|cc|}
\hline Equation & Equation number \\
\hline$C_{\text {civil }}=1034.4 M_{\text {feed }}+1487 n_{\text {vessel }}$ & $(2)$ \\
\hline$C_{\text {mech }}=4329.6 M_{\text {feed }}{ }^{0.85}+1089.6 n_{\text {vessel }}$ & $(3)$ \\
\hline$C_{\text {electro }}=1.68 * 10^{6}+64.8 P_{\text {feed }} M_{\text {feed }}$ & $(4)$ \\
\hline$C_{\text {membrane }}=1200 n_{\text {vessel }}$ & $(5)$ \\
\hline
\end{tabular}

where $\mathrm{C}_{\text {civil }}$ [\$] represents the cost for the buildings housing the plant, $\mathrm{C}_{\text {mech }}[\$]$ the cost for pumps, filters and piping system, $C_{\text {electro }}[\$]$ the costs for the energy supply systems and $\mathrm{C}_{\text {membrane }}[\$]$ the investment for the membrane modules. In all equations, $\mathrm{M}_{\text {feed }}$ is the total feed flow rate in $\left[\mathrm{m}^{3} / \mathrm{h}\right]$ and $\mathrm{P}_{\text {feed }}$ is the inlet feed pressure in [bar]. These correlations make reference to vessels with a membrane area of $30 \mathrm{~m}^{2}$. The capital costs are then linearly depreciated, the depreciation period is assumed equal to 30 years for the civil investment, 15 years for the mechanical and electro-technical equipment and 5 years for the membranes [38]. These costs are updated using the Chemical Engineering Plant Cost Index (CEPCI). A discount rate equal to $6 \%$ is considered for the calculation of the annuity, in line with typical values reported in the literature for water purification and desalination plants [36], [44]. Among the operating costs, the energy cost is calculated taking into account the pump energy consumption and an average energy consumption of the membrane system equal to $40 \mathrm{Wh} / \mathrm{m}^{3}$ feed [38]. The cost of chemicals is estimated as $0.020-0.025 \$ / \mathrm{m}^{3}$ of permeate [37]. Other costs including maintenance, quality control and daily operation are estimated to sum up to $2 \%$ of the capital costs [38].

\subsection{Crystallizer}

The treatment chain for the IEX spent brine includes two crystallization steps: one for the recovery of $\mathrm{Mg}(\mathrm{OH})_{2}$, the other for $\mathrm{Ca}(\mathrm{OH})_{2}$. A detailed simulation of the crystallizers is beyond the scope of this work: a simplified model based on mass balances was implemented to calculate the inlet flow rate and the outlet products flow rate. These figures are then used for the estimation of the economic parameters. The underlying assumption is that the hydroxide crystals produced via this process have the purity, the specific area and the size distribution suitable to be sold. In the present crystallization process, a first crystallization step is meant to separate the $\mathrm{Mg}^{2+}$ from the solution in the form of $\mathrm{Mg}(\mathrm{OH})_{2}$; the produced suspension from the first crystallizer is filtered to get the solid crystals and the filtration effluent is fed to a second 
crystallizer where $\mathrm{Ca}(\mathrm{OH})_{2}$ is produced and subsequently filtered. The investigated crystallizer is a plug-flow reactor, where the brine is fed at the entrance of the tube while the alkaline reactant (a $\mathrm{NaOH}$ solution) is injected into the tube in different equidistant points, in order to avoid too high supersaturation and to reduce the role of the primary nucleation. Because of the very low solubility of the two hydroxides, especially of $\mathrm{Mg}(\mathrm{OH})_{2}$, a conversion of $100 \%$ typically occurs in the reactors. Consequently, the total inlet molar flow rate of $\mathrm{Mg}^{2+}$ and $\mathrm{Ca}^{2+}$ is converted into an outlet molar flow rate of $\mathrm{Mg}(\mathrm{OH})_{2}$ and $\mathrm{Ca}(\mathrm{OH})_{2}$. Furthermore, the estimation of the alkaline solution flow rate needed for the two separation stages is particularly important: it is calculated multiplying the entering molar flow rates of $\mathrm{Mg}^{2+}$ and $\mathrm{Ca}^{2+}$, coming from the nanofiltration, by the stoichiometric coefficient (i.e. 2) and considering an excess of $10 \%$ with respect to the stoichiometric concentration. The volume flow rate is estimated assuming a concentration of the $\mathrm{NaOH}$ solution equal to $1 \mathrm{~mol} / \mathrm{l}$. For what concerns the economic estimations, the capital cost of the equipment is calculated via the Module Costing Technique starting from the purchasing cost of two crystallizers [42], one for each mineral, calculated as a function of the volume $\left[\mathrm{m}^{3}\right]$ and of two filters, calculated as a function of the area $\left[\mathrm{m}^{2}\right]$. A disc and drum filter is selected as filter unit since its maximum capacity (i.e. 300 $\mathrm{m}^{2}$ of filtration area) is higher than the one of a plate and frame filter (i.e. $80 \mathrm{~m}^{2}$ ). For the calculation of the annualized capital costs (CAPEX of the crystallization) a discount rate of $6 \%$ and a depreciation period of 20 years are assumed. The operating costs include the cost of the energy required by the pumps of the feed solution and the reactant solution and the energy required by the filter, considering two filtration stages, one for the $\operatorname{Mg}(\mathrm{OH})_{2}$ solution and one for the $\mathrm{Ca}(\mathrm{OH})_{2}$ solution.

\subsection{Multi-Effect Distillation}

The last model employed for this work describes the Multi-Effect Distillation process. The process has been investigated in detail in the literature [39], [40] and the model employed in the present work is extensively reported elsewhere [57]. The adopted MED plant has a forward feed arrangement (FF), because of the high operating concentrations and the high temperatures [41] and it is supposed to work in steady-state conditions. The model allows a full characterization of the flow rates, concentration and temperature profiles along the effects. The model inputs are the number of effects, the feed flow rate and salinity, the feed intake temperature, the steam temperature in the first effect and the temperature of the last effect. The main outputs are the heat exchanger areas of the evaporators, the preheater and the endcondenser, together with the steam flow rate required in the first effect. The steam flow rate 
allows estimating the thermal energy demand of the plant, which is given by the product of the steam flow rate and its latent heat at the corresponding pressure (in the present case at $1 \mathrm{bar}$ ). The model is able to simulate the behaviour of a plain MED or a MED coupled with a ThermoVapour Compressor (MED-TVC) and in this last case, the pressure of the motive steam is one of the inputs, while the output is the required motive steam flow rate. The technical model is fully coupled with an economic model, in which the estimation of the capital costs is performed via the application of the Module Costing Technique [42]. For the calculation of the CAPEX of the MED [\$/y], again, we assumed a discount rate of $6 \%$ and a depreciation period of 25 years [44]. Finally, the estimation of the operating costs is based on the thermal and electric energy cost and on data relevant to real plants [43].

\section{CASE STUDY UNDER INVESTIGATION AND RELEVANT MODEL INPUTS}

This section describes in detail the case study under investigation: it includes the description of the operating conditions used for the simulations, the parameters of the nanofiltration membranes (section 3.1), the geometric properties and the main economic inputs (section 3.2). In the presented case, the economic feasibility of the proposed treatment chain is evaluated comparing a global parameter, called Levelized Brine Cost (LBC), with the cost of the currently used regenerant solution, equal to $8 \mathrm{US} \$ / \mathrm{m}^{3}$. This cost corresponds to a $9 \%{ }^{\mathrm{w} / \mathrm{w}} \mathrm{NaCl}$-water solution, estimated considering a cost of the pure $\mathrm{NaCl}$ salt equal to $65 € /$ ton $(80.2 \mathrm{US} \$ /$ ton $)$ and a cost of water equal to $1 \mathrm{US} \$ / \mathrm{m}^{3}$.

The LBC is given by the sum of the annualized capital and operating costs minus the revenues of the chain by-products, divided by the amount of concentrate brine produced by the MED unit (see equation (6)).

$$
L B C\left[\frac{\$}{m^{3}}\right]=\frac{\text { CAPEX }+ \text { OPEX }- \text { Revenue }_{\mathrm{Mg}_{(\mathrm{OH})_{2}}-\text { Revenue }_{\mathrm{Ca}(\mathrm{OH})_{2}}-\text { Revenue }_{\mathrm{H}_{2} \mathrm{O}}}}{M_{\text {brine, } \mathrm{MED}}}
$$

The definition of the LBC as the measure of the economic feasibility of the treatment chain is built in analogy with the definition of the Levelized Water Cost (LWC) for desalination plants. Therefore, several works in literature report techno-economic analyses of desalination processes, whose profitability is defined through the LWC, which includes the total costs of the technology and the distillate productivity of the plant [44].

The composition and the flow rate of the effluent, reported in Table 3, are based on the investigated case study (regeneration of the IEX resins in EVIDES water softening plant). 
Regarding the target product, the concentrate solution produced by the MED and re-usable for the IEX regeneration must have a fixed concentration of $\mathrm{NaCl}$ equal to $90,000 \mathrm{ppm}(\sim 1,550$ $\mathrm{mol} / \mathrm{m}^{3}$ ). This concentration is used as a design parameter, together with the steam temperature, the number of effects and the feed flow rate and concentration, to calculate the required steam flow rate and the area of heat exchangers and preheaters.

Table 3. Feed flow rate and concentration values.

\begin{tabular}{cccccc}
\hline $\begin{array}{c}\mathbf{M}_{\text {feed }} \\
{\left[\mathrm{m}^{3} / \mathrm{h}\right]}\end{array}$ & $\begin{array}{c}\mathbf{C}_{\mathrm{Na}} \\
{\left[\mathrm{mol} / \mathrm{m}^{3}\right]}\end{array}$ & $\begin{array}{c}\mathbf{C}_{\mathrm{Cl}} \\
{\left[\mathrm{mol} / \mathrm{m}^{3}\right]}\end{array}$ & $\begin{array}{c}\mathbf{C}_{\mathbf{M g}} \\
{\left[\mathrm{mol} / \mathrm{m}^{3}\right]}\end{array}$ & $\begin{array}{c}\mathbf{C}_{\mathbf{C a}} \\
{\left[\mathrm{mol} / \mathrm{m}^{3}\right]}\end{array}$ & $\begin{array}{c}\mathbf{C s O 4} \\
{\left[\mathrm{mol} / \mathrm{m}^{3}\right]}\end{array}$ \\
\hline 130.0 & 173.9 & 662.2 & 55.6 & 191.7 & 3.125 \\
\hline
\end{tabular}

\subsection{NF membrane properties}

For what concerns the NF membranes, several works in the literature are devoted to estimating the parameters (pore radius $\mathrm{r}_{\text {pore }}$, active layer membrane thickness $\delta_{\mathrm{m}}$, pore dielectric constant $\varepsilon_{\text {pore }}$ and charge density $\mathrm{X}_{\mathrm{d}}$ ) in different operating conditions. These values are strongly dependent on the solutes and determine the membrane performances, in particular the solute rejections and the recovery. For the present study, the set of membrane parameters is based on previous literature works concerning NF units fed by solutions with a composition similar to the one under investigation. Each property is considered independent of the others, as already stated in [45]. In particular, the membrane pore radius is often found to be between 0.4 and 0.5 nm [46], [53], [63], while some studies showed that the active membrane thickness depends on the solute size, because of the complex and interconnected internal structure of the pores [47]. However, the most common range of membrane thickness is from 1 to $7 \mu \mathrm{m}$.

Regarding the dielectric pore constant ( $\left.\varepsilon_{\text {pore }}\right)$, if the dielectric constant variation between bulk and pore is neglected, the value of $\varepsilon_{\text {pore }}$ is taken equal to 80 . In presence of $\mathrm{NaCl}$, this is often found around 40 (values of 33.7 and 42.2 were found in literature for commercial membranes), while in presence of $\mathrm{Mg}^{2+}$ it has typically higher values (values of 46.6 and 65.1 were found) [48], [63]. Next, the estimation of the charge density is a much discussed topic in literature, since its value depends not only on the solutes but also on their concentration. Most of the membranes are negatively charged at a neutral $\mathrm{pH}$ and the charge is given by the dissociation of sulfonic and/or carboxylic acid groups [49]. However, the membrane charge is significantly affected by the $\mathrm{pH}$ of the fed solution and its ionic strength. Therefore, the active sites can be more protonated or deprotonated varying the solution $\mathrm{pH}$ and other charged sites can be given 
by the adsorption of the ions present in the solution [50]. For example, Mazzoni et al. showed the trend of the membrane charge density with the concentration for $\mathrm{NaCl}$ and for $\mathrm{CaCl}_{2}$ in presence of commercial membranes [51]. This study, in agreement with others reported in [52], demonstrated that in a very wide range of concentration of $\mathrm{CaCl}_{2}$, the membrane presents a positive charge because of the preferential adsorption of $\mathrm{Ca}^{2+}$ on the membrane surface. Schaep et al. showed how the presence of $\mathrm{Mg}^{2+}$ ions leads to a positively charged membrane in a wide range of concentration [53]. This study also stated that, in presence of more ions, each component adds its own independent contribution to the overall membrane charge. In the case under investigation, the presence of $\mathrm{Mg}^{2+}$ and $\mathrm{Ca}^{2+}$ in concentration much higher than in seawater may likely generate a positive charge on the membrane surface, which corresponds to higher values of $\mathrm{Mg}^{2+}$ and $\mathrm{Ca}^{2+}$ rejections. Having said that, in order to characterize a highlyperforming membrane in presence of the investigated solution, the values of $r_{\text {pore }}, \delta_{\mathrm{m}}$ and $\varepsilon_{\text {pore }}$ are taken equal to the ones considered in previous works for seawater [62] and equal to 0.45 $\mathrm{nm}, 3 \mu \mathrm{m}$ and 56.5 respectively. In fact, the components of the investigated brine are the same of seawater and these values proved to be much performing also for the case under investigation (see section 4.1). Conversely, the value of charge density is assumed equal to $40 \mathrm{~mol} / \mathrm{m}^{3}$, since the concentrations are very different from seawater (much higher concentration of $\mathrm{Mg}^{2+}$ and $\left.\mathrm{Ca}^{2+}\right)$ and the value used by Roy et al. in [62] $\left(-80 \mathrm{~mol} / \mathrm{m}^{3}\right)$ may not be suitable for this system. In this way, it is possible to achieve values of rejection of $\mathrm{Mg}^{2+}, \mathrm{Ca}^{2+}$ and $\mathrm{SO}_{4}{ }^{2-}$ within the typical intervals reported for the NF units integrated in desalination processes, i.e. from $85 \%$ to $97 \%$ for $\mathrm{Mg}^{2+}$, from 70 to $97 \%$ for $\mathrm{Ca}^{2+}$ and higher than $95 \%$ for $\mathrm{SO}_{4}{ }^{2-}$ [54]. The values of the membrane parameters employed in the present work are reported in Table 4.

Table 4. Employed NF membrane parameters.

\begin{tabular}{cccc}
\hline $\begin{array}{c}\mathbf{r}_{\text {pore }} \\
{[\mathrm{nm}]}\end{array}$ & $\begin{array}{c}\boldsymbol{\delta}_{\mathbf{m}} \\
{[\mu \mathrm{m}]}\end{array}$ & $\begin{array}{c}\boldsymbol{\varepsilon}_{\text {pore }} \\
{[-]}\end{array}$ & $\begin{array}{c}\mathbf{X}_{\mathbf{d}} \\
{\left[\mathrm{mol} / \mathrm{m}^{3}\right]}\end{array}$ \\
\hline 0.45 & 3 & 56.5 & 40 \\
\hline
\end{tabular}

\subsection{Geometric properties of the units and main economic parameters}

For what concerns the second part of the results, which is focused on the economic analysis of the whole treatment chain, the basic geometry of the plants has to be defined. With this respect, 
the area of the NF membrane leaf is equal to $1 \times 1 \mathrm{~m}^{2}$ and the feed spacer thickness is taken equal to $0.5 \mathrm{~mm}$. The specifications of the crystallizer cannot be reported due to a confidentiality agreement with the company working on the joint development of the system. Regarding the MED, a plain MED, fed by waste heat with a pressure of 1 bar, is considered and the number of effects is fixed and equal to 13, as this is the optimal MED plant size under these operating conditions [57]. Regarding the economic analysis, the operating costs and the revenues depend on the cost of the alkaline reactant used in the crystallizer, on the selling price of the hydroxides and of the water and on the thermal and electric energy costs. These values are reported in Table 5.

Table 5. Costs of the reactants, utilities and products used for the economic analysis.

\begin{tabular}{|c|c|c|c|c|c|}
\hline $\begin{array}{c}\text { Cost }_{\mathrm{NaOH}} \\
{[\$ / \text { ton }]}\end{array}$ & $\begin{array}{c}\text { Price }_{\mathrm{Mg}(\mathrm{OH}) 2} \\
{[\$ / \text { ton }]}\end{array}$ & $\begin{array}{c}\text { PriceCa(OH)2 } \\
\text { [\$/ton] }\end{array}$ & $\begin{array}{c}\text { Price }_{w a t e r} \\
{\left[\$ / \mathrm{m}^{3}\right]}\end{array}$ & $\begin{array}{c}\text { Cost therm.energy } \\
{\left[\$ / \mathrm{kWh}_{\mathrm{th}}\right]}\end{array}$ & $\begin{array}{c}\text { Costel.energy } \\
{\left[\$ / \mathrm{kWh}_{\mathrm{el}}\right]}\end{array}$ \\
\hline 350 & 1200 & 300 & 1 & 0.01 & 0.06 \\
\hline
\end{tabular}

\section{RESULTS AND DISCUSSION}

The results collected within this work are subdivided into two parts: in the first part (section 4.1), the results relevant to the NF plant at different feed pressures and recovery values are reported, with a particular focus on the impact of the electric energy consumption on the total cost. Conversely, in the second part (section 4.2) the overall treatment chain is analysed from the energetic and economic point of view, through the estimation of the costs relevant to each unit in the system (NF, crystallizer and MED) and the calculation of the Levelized Brine Cost (LBC).

\subsection{Influence of the Operating Conditions of the Nanofiltration Unit}

In the following, the NF unit performances are investigated to identify the most suitable operating conditions to be adopted for the treatment of the brine produced by IEX resins. The typical recovery of a NF unit used in desalination plants or in the removal of pollutants from water is very high $(\sim 80 \%)$, since in those cases the useful product is the permeate [54-56]. In this case, both permeate and retentate (after the crystallization steps) are fed to the MED unit, thus it may be interesting to investigate also NF units at a lower recovery. The role of feed pressure and recovery is investigated with respect to the performance of the whole NF plant. For a system with a fixed recovery $(25 \%)$, the impact of the feed pressure on the ion rejection 
and on the overall cost of the plant is detected and the results are reported in Figure 6. In this case, three pressures are considered, i.e. 20, 30 and 40 bar. Notably, it is not possible to consider lower pressures, since the high concentrations of the brine lead to a very high osmotic pressure. At the same time, higher pressures are not investigated since the maximum operating pressure in a NF system is generally around 40 bar. Figure 6a depicts the trends of the ions' rejection vs. the feed pressure, with a fixed recovery of $25 \%$ and with the feed flow rate and concentration values reported in Table 3. Notably, the higher the feed pressure, the higher the rejection of every ion. This is expected, because a higher feed pressure leads to a higher water flux through the membrane, when the pore radius and the membrane thickness are fixed. However, the most significant increase of the rejection is reported for $\mathrm{Na}^{+}$and $\mathrm{Cl}^{-}$, while the $\mathrm{Ca}^{2+}$ rejection growth is less than $10 \%$ and the change in $\mathrm{Mg}^{2+}$ and $\mathrm{SO}_{4}{ }^{2-}$ rejection is almost negligible. Figure $6 \mathrm{~b}$ reports the terms of cost of the NF plant at different $\mathrm{P}_{\text {feed }}$, estimated according to the equations reported in section 2.1.2. Firstly, the capital costs (annualized via linear depreciation) slightly decrease as the feed pressure increases, because the water flux through the membrane grows and the number of vessels in parallel required for the fixed recovery is lower. At the same time, the cost relevant to the energy supply system $\left(\mathrm{C}_{\text {electro }}\right)$ increases with the feed pressure and this effect becomes predominant at higher pressures, leading to a slight increase of the total capital costs. Conversely, all operating costs, especially the energy consumption, rise. Since the latter effect is prominent, the total annualized cost of the NF unit increases with the feed pressure.
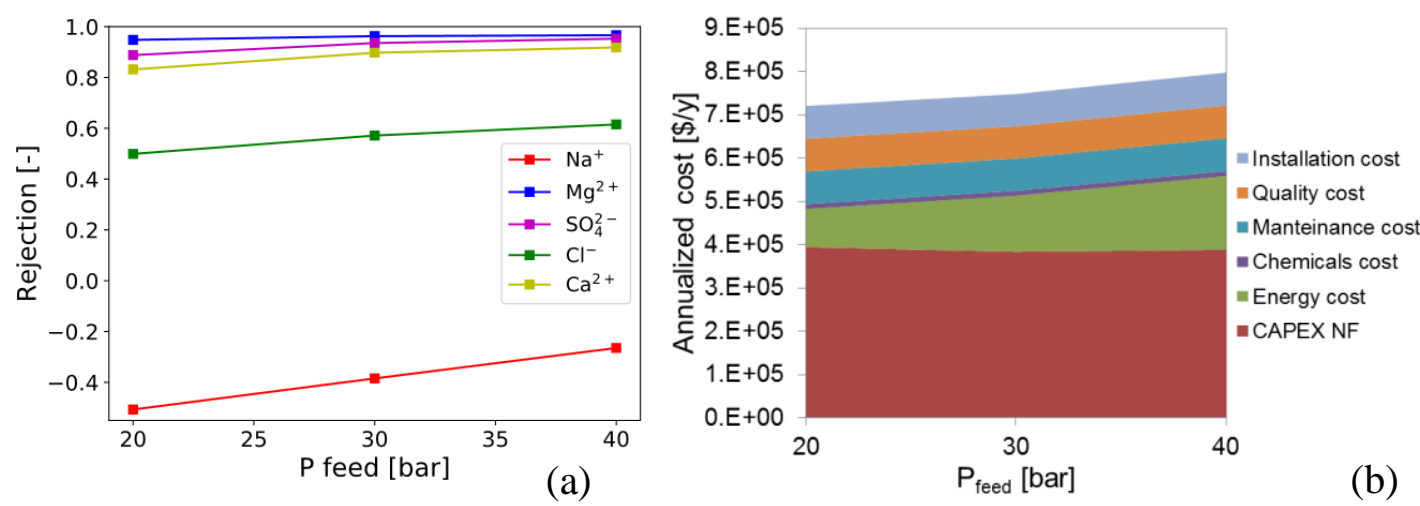

Figure 6. Ions' rejection (a) and analysis of the cost terms of the nanofiltration plant (b) at different $\mathrm{P}_{\text {feed }}$ [bar]. (Recovery=25\%; $\mathrm{M}_{\text {feed }}$ and $\mathrm{C}_{\text {bulk }}$ values reported in Table 3 and membrane properties reported in Table 4)

Moreover, the effect of different recovery ratios is studied ranging from $25 \%$ up to $65 \%$ (i.e. $25 \%, 50 \%$ and $65 \%$ ). The range is limited up to a maximum recovery of $65 \%$ because, with a single stage, higher recoveries would require operating pressures higher than 40 bar. Figure 7 
shows the trends of the ions' rejection vs. the recovery at a feed pressure equal to 40 bar and with the values of feed flow rate and concentrations reported in Table 3 . The rejection decreases as the recovery rises, for all ions apart from $\mathrm{Na}^{+}$, whose rejection is almost constant. The rejection trends are explicable considering that, at higher recovery, the required number of vessels in parallel is higher and each vessel is crossed by a lower feed flow rate. This leads to a growing concentration polarization, which causes a higher driving force for the ion fluxes through the membrane and a lower rejection.

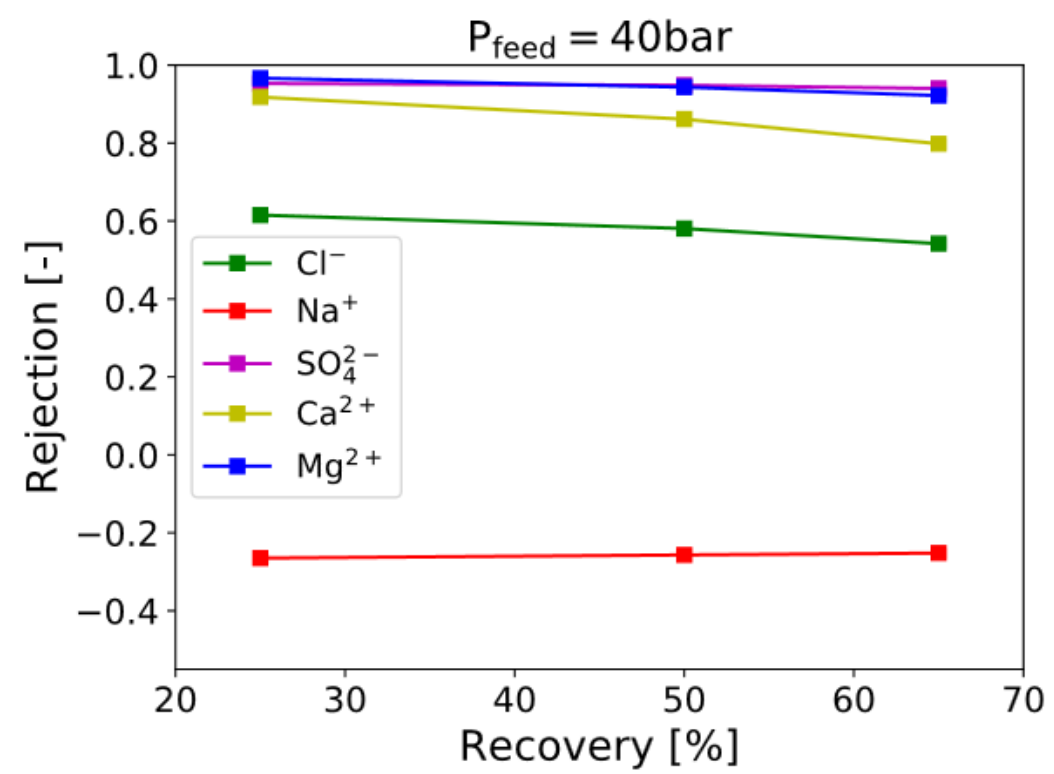

Figure 7. Ions' rejection at different recovery ratios. ( $\mathrm{P}_{\text {feed }}=40$ bar; $\mathrm{M}_{\text {feed }}$ and $\mathrm{C}_{\text {bulk }}$ values reported in Table 3 and membrane properties reported in Table 4)

\subsection{Treatment Chain}

\subsubsection{Economic analysis and assessment of the energy demand varying the NF recovery}

The following section reports the results of the economic analysis of the whole chain and the assessment of the energy requirements, collected at three different NF recovery values. As shown in Figure 6b, for the present case, the most convenient condition for the NF plant is at the lowest feed pressure. For this reason, the comparison is carried out at different NF feed pressures, i.e. 20 bar for a recovery of $25 \%, 30$ bar for $50 \%$ and 40 bar for $65 \%$.

The variation of the recovery has several consequences on the chain performances, which are analysed from the economic and energetic point of view in Figure 8 and Figure 10. Regarding the NF plant, its size (i.e. the number of required vessels) increases with the recovery and the ion rejection decreases (as shown in Figure 7). The first effect leads to a growth of the total 
capital costs relevant to the NF unit, while the operating costs increase because the systems work at higher feed pressure, as shown in Figure 8. Moreover, for the definition itself of recovery, its rise corresponds to a reduction of the NF retentate flow rate, which is fed to the crystallizer. This causes the reduction of the crystallizer volume and, consequently, the drop of both capital and operating costs. However, these variations are relatively small (compared to other costs) and are not very evident in the cost overview reported in Figure 8. At the same time, the diminution of the bivalent ion rejection with the recovery has various effects. Since the concentration of bivalent ions in the NF retentate decreases, the required $\mathrm{NaOH}$ solution flow rate decreases, but the produced flow rates of $\mathrm{Mg}(\mathrm{OH})_{2}$ and $\mathrm{Ca}(\mathrm{OH})_{2}$ are lower. From the economic point of view, in the crystallizer, we found a simultaneous decrease of the expenses due to the reactant used in the crystallizer and of the revenues due to the minerals' production, with the rise of the recovery. It has to be said that the cost of the $\mathrm{NaOH}$ solution constitutes an operating cost in the crystallization stage; however, it is separated in Figure 8 on purpose in order to highlight its weight in the treatment chain. Furthermore, the MED feed is significantly affected by the NF recovery, since it is given by the NF permeate mixed with the effluent from the crystallizer. The flow rate fed to the MED slightly decreases with the recovery, because of the different $\mathrm{NaOH}$-water solution flow rate. The $\mathrm{NaCl}$ concentration of the MED feed depends on the $\mathrm{NaOH}$ solution concentration and, assuming a fixed $\mathrm{NaOH}$ concentration equal to $1 \mathrm{M}$, the MED feed concentration decreases at higher recovery values, because of the higher permeate flow rates. At the same time, the higher permeate flow rate causes the growth of the concentration of bivalent ions in the MED feed, and consequently in the MED brine. This is because the bivalent ions' concentration in the NF permeate is higher than in the crystallizer effluent and the rejection worsens when recovery increases. However, these concentrations are very low in all cases and for the chain with a recovery of $25 \%$, the concentrations of $\mathrm{Mg}^{2+}$ and $\mathrm{Ca}^{2+}$ in the recirculated brine are around $1.5 \mathrm{~mol} / \mathrm{m}^{3}$ and $18 \mathrm{~mol} / \mathrm{m}^{3}$, which are less than $10 \%$ of their concentration in the initial resins effluent.

In terms of costs, the decrease of the feed flow rate and $\mathrm{NaCl}$ concentration with the recovery growth causes a slight reduction of both capital and operating costs relevant to the MED plant. Concerning the global costs, Figure 8 clearly shows that both the expenses and the revenues decrease with the increase of the recovery. It has also to be underlined that the costs relevant (i) to the reactant employed in the crystallizer and (ii) to the MED unit (mostly thermal energy cost) play the most prominent role among the expenses. Regarding the capital costs, the MED covers the highest percentage, while the capital costs of the NF unit and the crystallizers, which include also the filter cost, represent a very small fraction of the total (the cost of the crystallizer 
is almost negligible). Turning to the revenues, these are found to play a crucial role for the feasibility of the system, especially the ones due to the minerals production. Notably, although the price of the $\operatorname{Mg}(\mathrm{OH})_{2}$ is much higher than that of $\mathrm{Ca}(\mathrm{OH})_{2}$, the net difference in their concentration in the effluent makes their revenues comparable and their sum is similar to or even higher (at low recovery) than the total cost of the $\mathrm{NaOH}$ solution. Also the revenue coming from the water production in the MED is significant, although it is much lower than the other two terms, as expected. Overall, the total cost is given by the difference between the annualized expenses (column on the left for each recovery value) and the annualized revenues (column on the right for each recovery value). The annualized cost is almost constant across the three cases. This is mostly due to the fact that, in all scenarios, the dominant terms are the cost of the $\mathrm{NaOH}$ solution and the revenues given by the minerals' production. These terms are almost balanced and this leads to a relatively stable total cost.

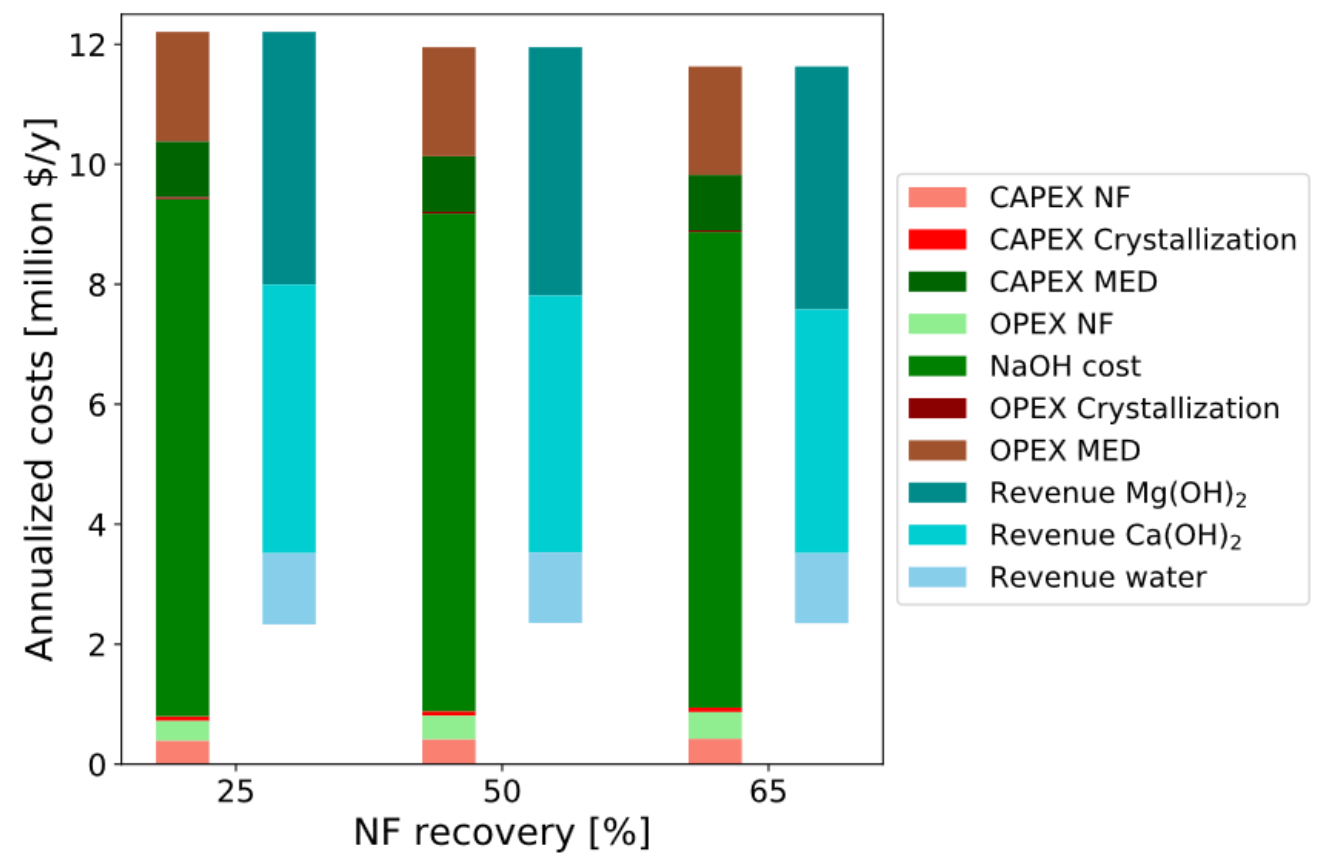

Figure 8. Annualized costs $[\$ / y]$ relevant to each unit in the treatment chain for three NF recovery values.

On the one hand, this analysis highlights the role of nanofiltration membranes, whose rejection to the different ions has a crucial role for the revenue estimation. Therefore, from the practical point of view, the membrane selection plays a fundamental role for the definition of the performances of the whole treatment system. On the other hand, it is worth noting the critical weight of the cost of the alkaline solution. Even if, in the presented cases, the revenues counterbalance the expenditure for the reactant, less expensive alternatives may be considered to further reduce the total costs. However, it has to be said that the $\mathrm{NaOH}$ solution is particularly 
advantageous because it ensures the production of pure hydroxide crystals and, importantly, it does not add other chemicals to the solution than $\mathrm{Na}^{+}$, whose excess can be neutralized with $\mathrm{HCl}$ producing $\mathrm{NaCl}$.

Moreover, in order to assess the feasibility of the treatment chain, another aspect to be considered is the productivity of the system, i.e. the concentrate solution ( $\mathrm{M}_{\text {brine,MED) produced }}$ by the MED, which is the main product of the chain (Figure 9a). Also in this case, the recovery plays a role because the concentration of $\mathrm{NaCl}$ in the solution fed to the MED changes. In particular, the MED inlet concentration decreases with the recovery, while the outlet concentration of the MED brine is fixed and equal to $90,000 \mathrm{ppm}$ in all cases. Therefore, according to the global mass balance in the MED unit, the produced concentrate flow rate results lower at a higher recovery. The combination of these terms leads to the definition of the Levelized Brine Cost (LBC), reported in Figure 9b. Notably, the decrease of the produced

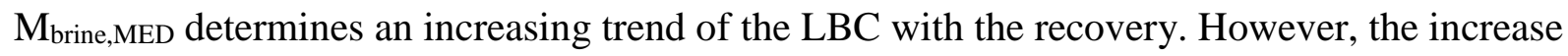
is relatively moderate and the maximum value, at the maximum recovery, is around $5.4 \$ 1 \mathrm{~m}^{3}$, while the minimum LBC (at a recovery of $25 \%$ ) is equal to $4.9 \$ / \mathrm{m}^{3}$. This makes the technology very competitive with the state of the art, since currently, a fresh solution of $\mathrm{NaCl}$ is provided for each regeneration cycle at a cost of $8 \$ / \mathrm{m}^{3}$ [57]. Thus, the proposed treatment chain reduces the consumption of raw materials (i.e. $\mathrm{NaCl}$ and pure water) and the disposal of brines into the environment, and is also more convenient than the current system from the economic point of view.
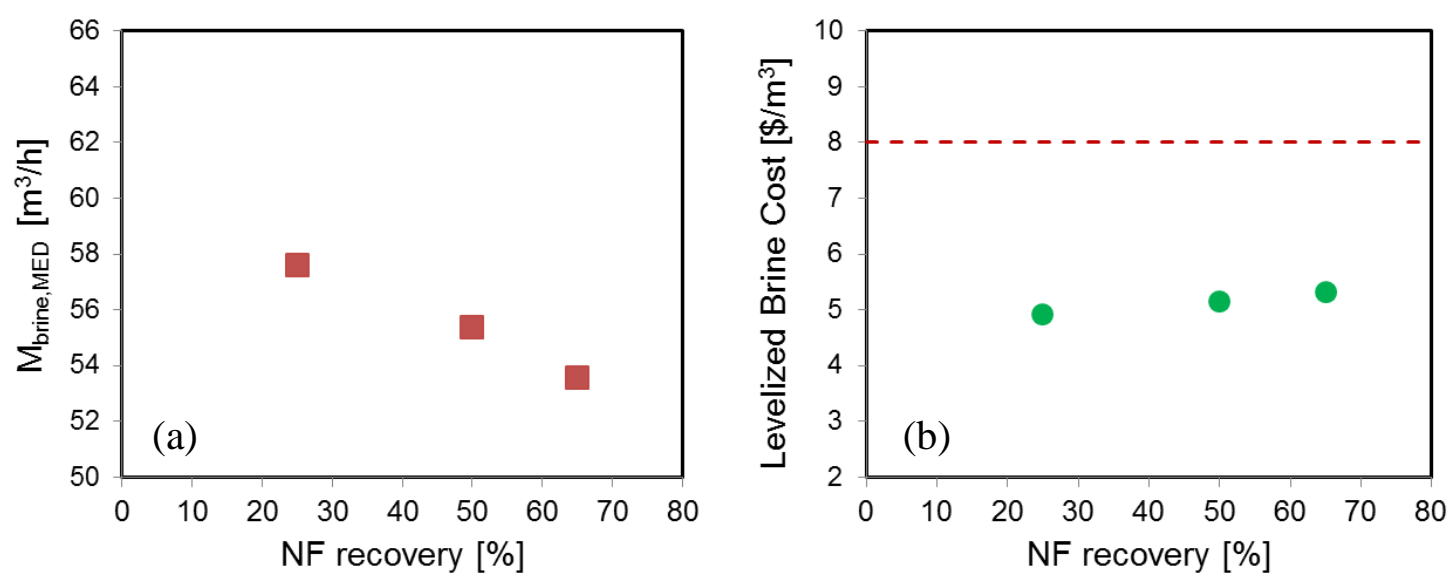

Figure 9. Produced brine flow rate (in the MED) $\left[\mathrm{m}^{3} / \mathrm{h}\right]$ vs. the NF recovery (a) and Levelized Brine Cost $\left[\$ / \mathrm{m}^{3}\right]$ vs. the NF recovery (b). In chart (b), the red dashed line corresponds to the current cost of the fresh regenerant solution.

In relation to the energy demand, Figure 10a reports the electricity requirement of each unit, while Figure $10 \mathrm{~b}$ shows the total electric and thermal demands. Notably, thermal consumption 
is driven by the MED unit only. The electric energy required by nanofiltration is given by the pumping energy and a general consumption for the membrane system. This last term depends on the feed flow rate, so it is constant in the three cases, while the pumping energy depends on the feed pressure, thus it rises with the recovery. The electric energy required to pump the feed in the crystallizer decreases when the recovery increases, however this term is very low, because of the low pressure required at the crystallizer inlet (mostly depending on the pressure drops in the nozzles). The electric energy demand of the filtration system is also calculated, starting from the energy consumption data given by the supplier for a certain filter size and scaling this value with the flow rate. In particular, the energy requirement of the filtration system slightly decreases with the NF recovery. Finally, both thermic and electric energy demand of the MED unit show a decreasing trend, since the produced distillate flow rate decreases at higher value of the NF recovery. Overall, the total electric energy requirement increases with the recovery, because of the increase of the pumping energy in the NF unit (Figure 10b). Conversely, the thermal energy consumption decreases with the NF recovery, since the only contribution is given by the MED unit.
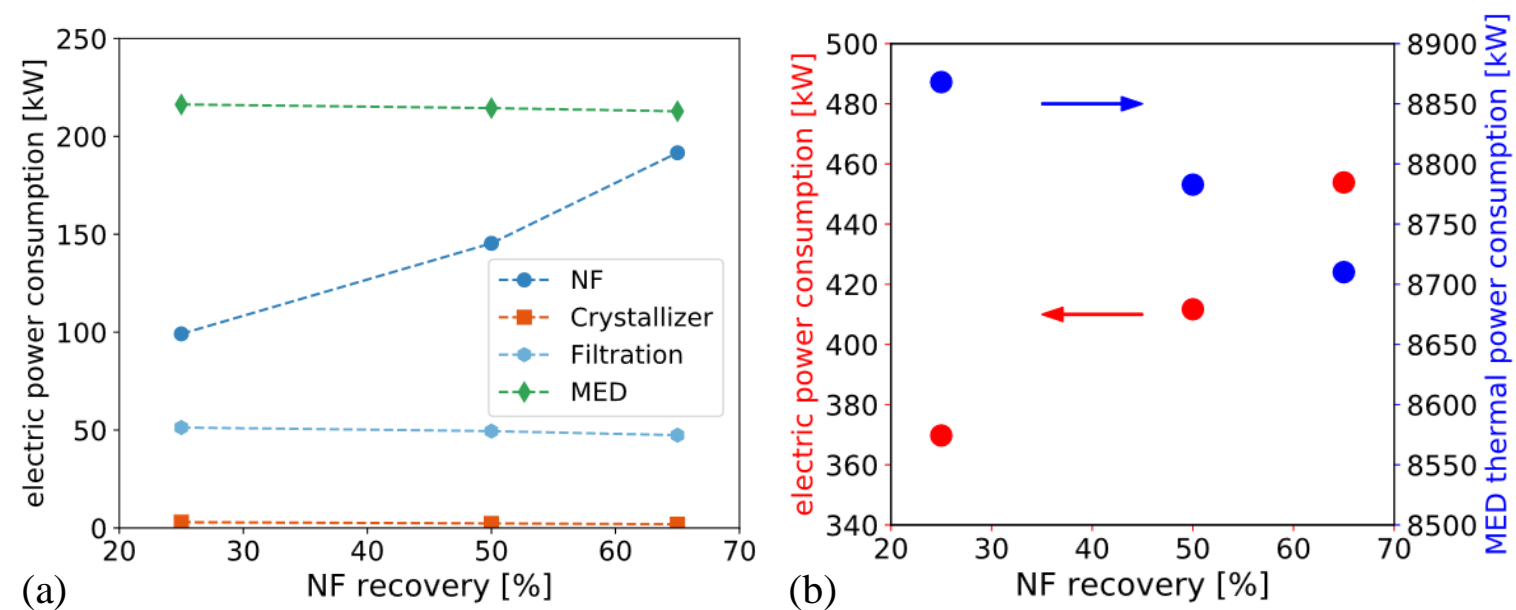

Figure 10. Electric power consumption of the treatment chain for the three NF recovery values (a) and overall thermal (due to MED only) and electric power consumption vs the recovery (b).

Overall, our analysis shows that the chain including the NF plant with the lowest recovery $(25 \%)$ is the best performing from an economic point of view, since it corresponds to the lowest LBC and it allows for reducing the amount of bivalent ions in the recirculated regenerant solution. Regarding the energy requirements, this system presents the lowest electricity demand but the highest thermal demand. However, since the real case study provides the presence of low-grade waste heat at a low cost, a higher heat demand can be met within the feasibility range of LBC. 
In Figure 11 the operating costs are compared for one case (recovery equal to $25 \%$ ), in order to evaluate the role of the energy costs. Since Figure 8 showed that the expense due to the reactant in the crystallizer and the revenues coming from $\mathrm{Mg}(\mathrm{OH})_{2}$ and $\mathrm{Ca}(\mathrm{OH})_{2}$ production are almost balanced, these terms were excluded. It is worth noting that the main term of cost corresponds to the thermal energy required by the MED unit, which covers more than $30 \%$ of the total. This is due to the fact that the thermal energy requirement is much higher (around $60 \mathrm{kWh} / \mathrm{m}^{3}$ dist,chain) than the electric energy requirement of NF (around $1 \mathrm{kWh} / \mathrm{m}^{3}$ dist,chain, which corresponds to

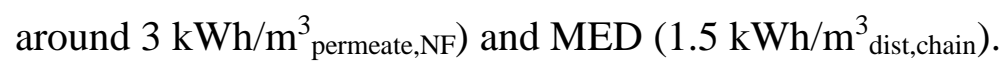

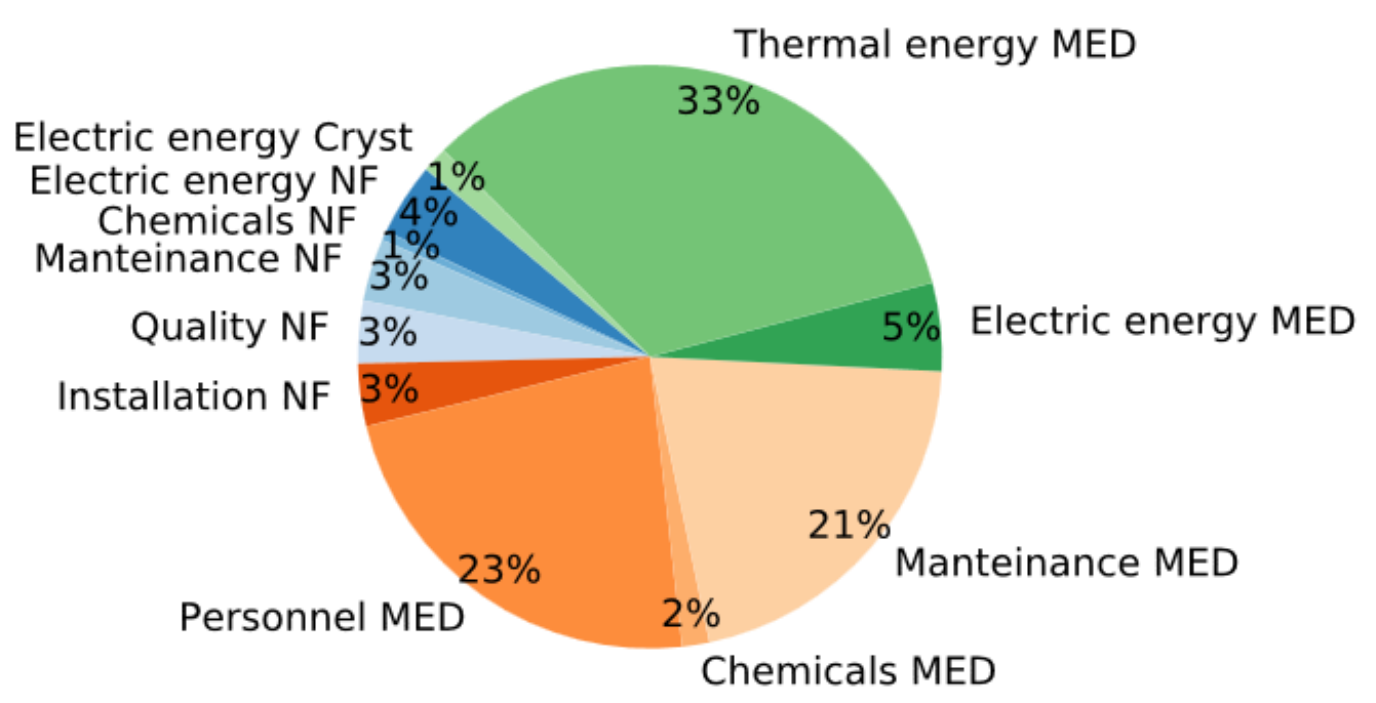

Figure 11. Main operating costs of the treatment chain, excluding the cost of the $\mathrm{NaOH}$ solution.

This analysis shows that the specific cost of the thermal energy may have a crucial impact on the total cost and the utilization of waste heat allows for reducing significantly the LBC.

\subsubsection{Sensitivity analyses}

\subsubsection{Sensitivity analysis on the Estimation of CAPEX and Operating Costs}

The estimation of the capital costs is performed via literature correlation or using data provided by technology suppliers. However, the degree of uncertainty in these estimations may be relatively significant. For this reason, a sensitivity analysis on the capital costs is performed, introducing a variation of $50 \%$ in the total capex and evaluating the corresponding LBC variation. The results are reported in Figure 12, where the error bars correspond to the maximum and the minimum calculated LBC. It is remarkable that the LBC variation is around $30 \%$, even 
for a variation of the total capital cost of $50 \%$. The trend of the LBC with the NF recovery remains the same and the maximum calculated LBC is still lower than $8 \$ / \mathrm{m}^{3}$.

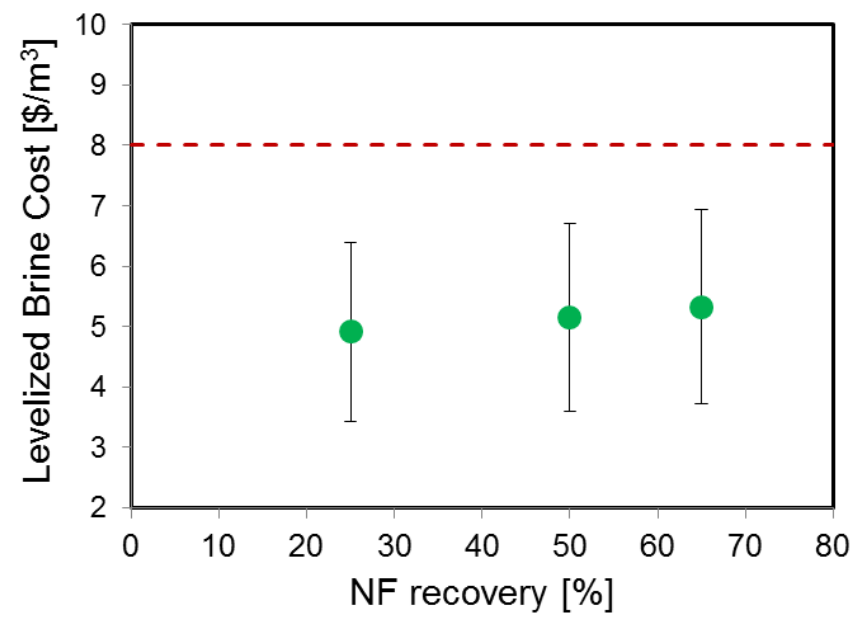

Figure 12. Sensitivity of the Levelized Brine Cost $\left[\$ / \mathrm{m}^{3}\right]$ on the capital costs estimation. Bars are related to a $\pm 50 \%$ of total CAPEX.

Moreover, it is interesting to evaluate the impact of the variation of the materials' price on the overall costs, in order to identify the key components of the system. This analysis is performed for the scenario with a recovery of $25 \%$ and the results are shown in Figure 13. In this figure the effect of $\mathrm{NaOH}$ cost and of $\mathrm{Mg}(\mathrm{OH})_{2}, \mathrm{Ca}(\mathrm{OH})_{2}$ and water selling prices is reported. The red line indicates a $\mathrm{LBC}$ variation leading to a $\mathrm{LBC}$ equal to the current cost of the regenerant solution. It is evident that the cost of $\mathrm{NaOH}$ is the prominent term in the definition of the $\mathrm{LBC}$ : a $\mathrm{NaOH}$ cost increase of $50 \%$ corresponds to a LBC increase of around $180 \%$. This strong dependency is somehow expected on the basis of the data shown in Figure 8. Moreover, the effect of the variation of $\mathrm{Mg}(\mathrm{OH})_{2}$ and $\mathrm{Ca}(\mathrm{OH})_{2}$ selling price is comparable, although the specific prices are very different (the price of $\mathrm{Ca}(\mathrm{OH})_{2}$ is varied from 150 to $450 \$$ /ton, while the price of $\mathrm{Mg}(\mathrm{OH})_{2}$ from 600 to 1800 \$/ton): this is due to the fact that they have very different concentrations in the NF retentate. Finally, the impact of the water selling price is much lower compared to the other terms and its variation of $50 \%$ gives a variation of the LBC of around $25 \%$. 


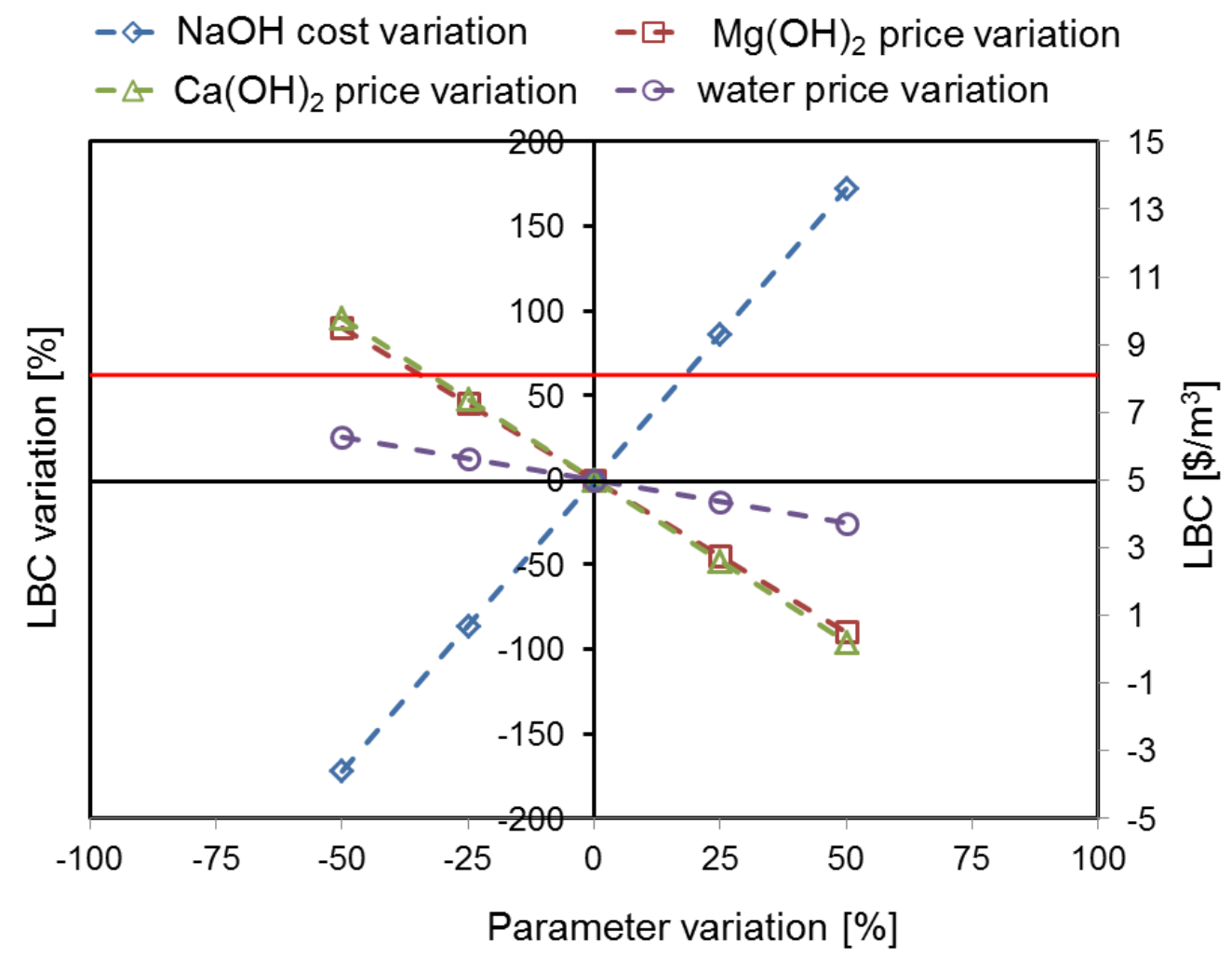

Figure 13. Sensitivity analysis on the cost of the reactant $\mathrm{NaOH}$ and on the selling price of $\mathrm{Mg}(\mathrm{OH})_{2}, \mathrm{Ca}(\mathrm{OH})_{2}$ and water for the case of recovery equal to $25 \%$.

\subsubsection{Sensitivity analysis on the feed flow rate $M_{\text {feed }}$}

The sensitivity analysis on the feed flow rate aims at investigating how much economies of scale may affect the overall cost of the treatment chain and the relevant LBC. In all data shown so far, the feed flow rate is equal to $130 \mathrm{~m}^{3} / \mathrm{h}$, in line with the brine volumes produced by the regeneration of the IEX resins in a real water softening plant. However, the flow rates of waste effluents may be lower. It is well known that the specific cost of a generic plant increases when its size decreases because of economies of scale. For this reason, it is important to recognize a range of feed flow rates in which the treatment chain is still more economically advantageous than supplying the fresh regenerant solution. Figure 14 shows the LBC as a function of $\mathrm{M}_{\text {feed }}$ for the case of a recovery of $25 \%$. The LBC relevant to the whole treatment chain decreases as $M_{\text {feed }}$ increases, in agreement with economy of scale, and it shows very high values at very low

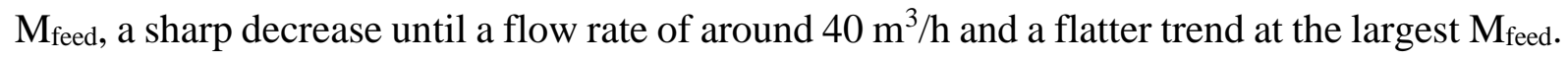
It is remarkable that all industrial cases with a $\mathrm{M}_{\text {feed }}$ higher than $50 \mathrm{~m}^{3} / \mathrm{h}$ would exhibit $\mathrm{LBC}$ values lower than the current value of the regenerant solution (i.e. $8 \$ / \mathrm{m}^{3}$ ), thus the proposed treatment chain results very competitive with the state of the art even in a wide range of operating conditions. 


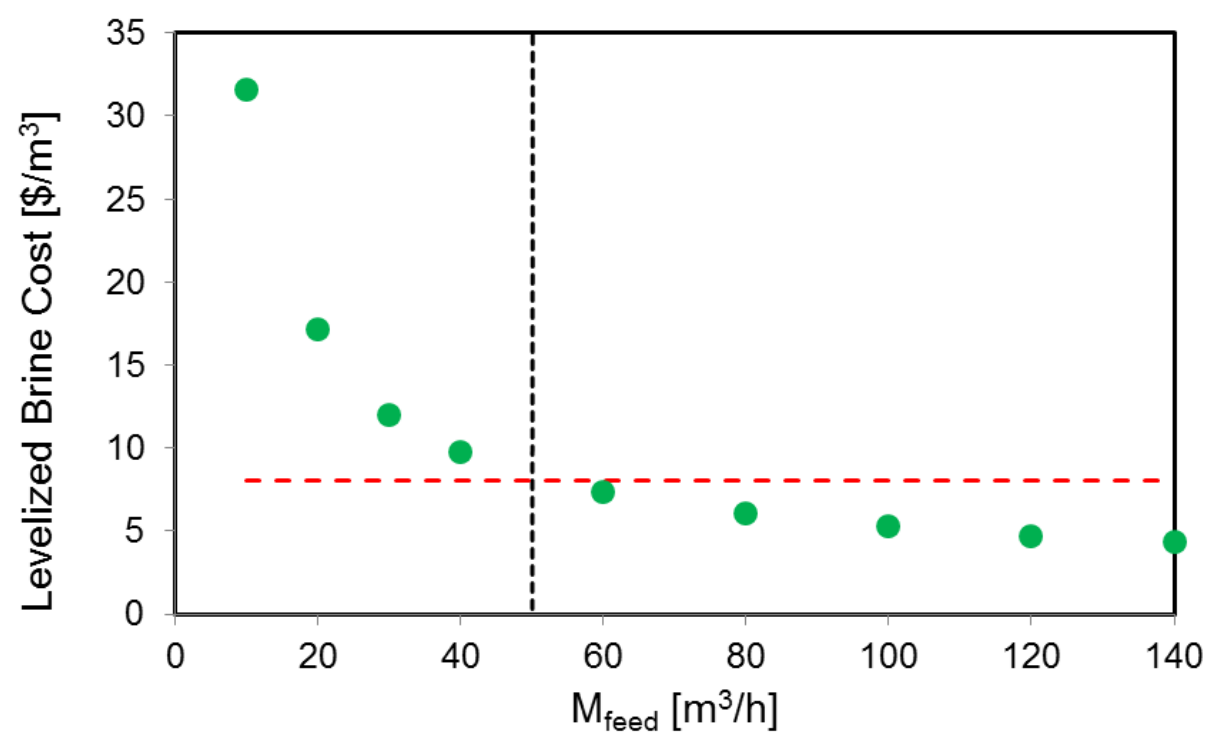

Figure 14. Variation of the Levelized Brine Cost $\left[\$ / \mathrm{m}^{3}\right]$ with $\mathrm{M}_{\mathrm{feed}}$.

\section{CONCLUSIONS}

Within the wide framework of the water-energy nexus, this work presents an 'energy for water' system in which a treatment chain is devised for the industrial wastewater produced by the regeneration of ion exchange resins in a water softening plant. A comprehensive technoeconomic assessment of the treatment chain, given by the combination of membrane and thermal desalination processes, and an evaluation of the energy requirements are presented for the first time. The chain aims at recovering the minerals in the form of hydroxides, and at producing the $\mathrm{NaCl}$-water solution re-usable as a reactant in the following regeneration cycle. The treatment chain includes nanofiltration, double-stage crystallization for the production of $\mathrm{Mg}(\mathrm{OH})_{2}$ and $\mathrm{Ca}(\mathrm{OH})_{2}$ and multi-effect distillation. A techno-economic model was set up for each unit and these models were interconnected via mass balances to simulate the integrated system. A global economic parameter, called Levelized Brine Cost (LBC) is used to assess the economic feasibility. Among the energy requirements of the system, the thermal energy required by the multi-effect distillation is the most relevant term (around $60 \mathrm{kWh}_{\mathrm{th}} / \mathrm{m}^{3}{ }_{\text {dist }}$ ), while the electric demand of the other units are between 1 and $3 \mathrm{kWh} / \mathrm{m}_{\text {dist }}^{3}$

Regarding the economic analysis, the multi-effect distillation covers the highest fraction of the capital costs, nevertheless the operating costs, and in particular the cost of the alkaline solution employed in the crystallizers, play the most important role. Notably, the revenues coming from the hydroxides production are almost able to counter-balance the expense due to the $\mathrm{NaOH}$ 
solution, especially at low nanofiltration recovery. Moreover, the analysis of the other operating cost terms, with the exclusion of the alkaline solution cost, showed that the total energy demand of the multi-effect distillation unit covers almost $40 \%$ of the OPEX. Therefore, the energy cost, and in particular the thermal energy cost, may be of crucial importance and the availability of waste heat at low cost allows a net reduction of the total cost of the treatment chain.

When the nanofiltration recovery increases, on the one hand, the membrane rejection worsens and since both revenues and expenditure decrease, the trend of the annualized total cost showed only a slight variation. On the other hand, the flow rate of the produced brine decreases: the combination of the variations of total cost and brine production leads to an increasing trend of the Levelized Brine Cost. However, for all scenarios investigated, the Levelized Brine Cost was found much lower than the current cost of the regenerant solution, thus proving the economic feasibility of the proposed treatment chain. The most feasible configuration presented a Levelized Brine Cost of $4.9 \$ / \mathrm{m}^{3}$ with a nanofiltration recovery of $25 \%$.

Finally, varying the feed flow rate $\mathrm{M}_{\text {feed, }}$ we found that, although economies of scale are responsible for higher Levelized Brine Cost at low flow rates, the proposed treatment solution remains economically advantageous for all processes with $M_{\text {feed }}$ higher than $50 \mathrm{~m}^{3} / \mathrm{h}$, which are typical sizes of industrial wastewater treatment plants.

Overall, this study presents an innovative system for the treatment and recycling of industrial wastewater, which was developed and parameterized for a practical application: the treatment of the spent regenerant solution of ion exchange resins employed for water softening. The analysis of the costs and energy demands of the single units in the treatment chain allows for identifying the most expensive (in terms of investment cost as well as operating cost) and the most energy-intensive units. The presented results give comprehensive indications concerning the economic feasibility of the investigated system and clearly indicate which aspects may be improved in the future.

\section{ACKNOWLEDGEMENTS}

This work was funded by the ZERO BRINE project (ZERO BRINE - Industrial Desalination - Resource Recovery - Circular Economy) - Horizon 2020 programme, Project Number: 730390: $\underline{\text { www.zerobrine.eu. }}$ 


\section{NOMENCLATURE}

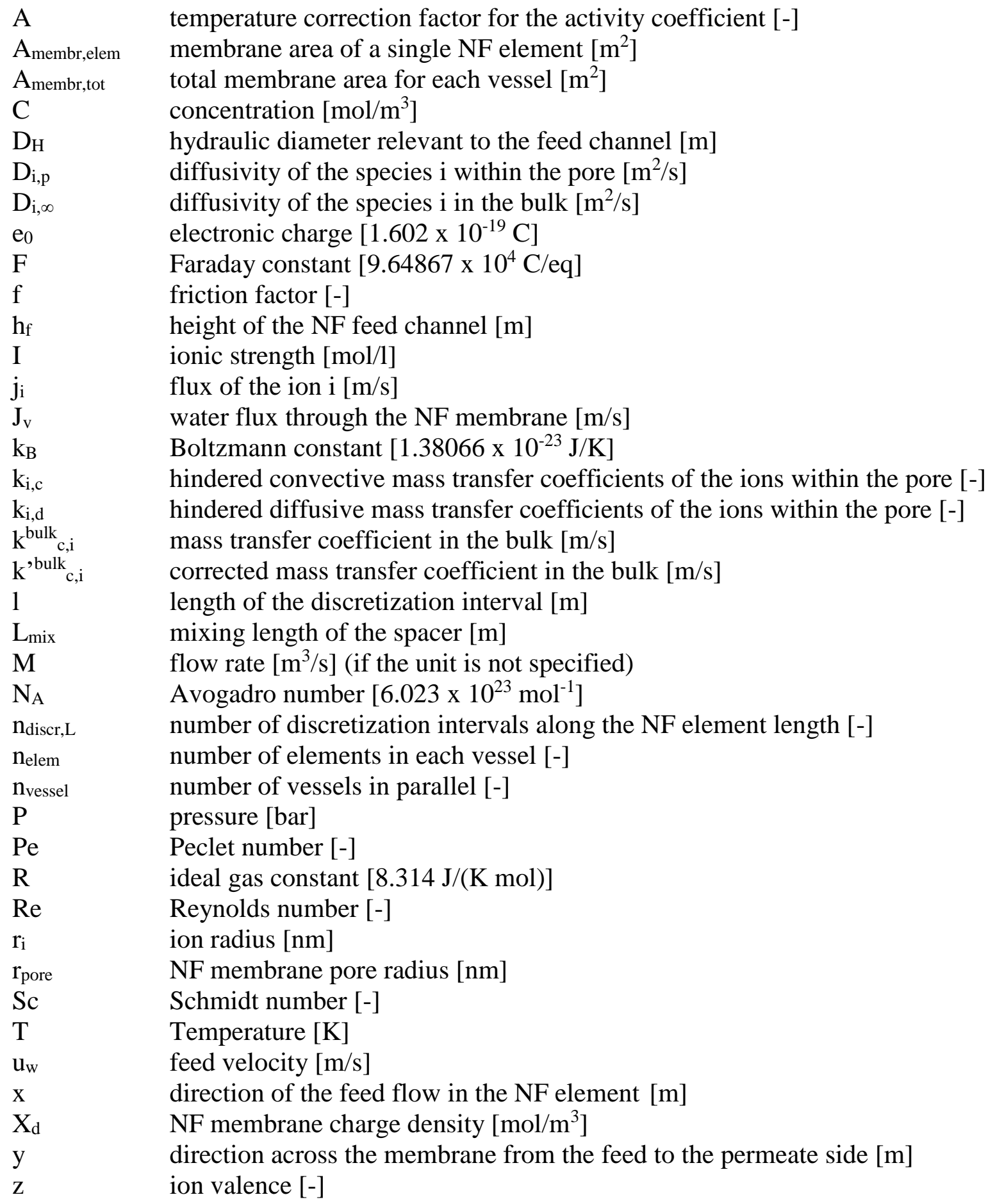

\section{Greek symbols}

$\begin{array}{ll}\gamma & \text { activity coefficient [-] } \\ \delta_{\mathrm{m}} & \text { NF membrane active layer thickness }[\mu \mathrm{m}]\end{array}$

$\Delta \Pi \quad$ osmotic pressure [bar]

$\Delta \mathrm{P}_{\text {losses }} \quad$ pressure losses along the element [bar]

$\Delta \mathrm{P} \quad$ net driving pressure [bar]

$\Delta \psi_{\mathrm{D}, \mathrm{bm}} \quad$ Donnan potential difference at the bulk-membrane interface [V]

$\Delta \psi_{\mathrm{D}, \mathrm{pm}} \quad$ Donnan potential difference at the permeate-membrane interface [V] 


$\begin{array}{ll}\Delta \mathrm{W} & \text { Born solvation energy barrier }[\mathrm{J}] \\ \varepsilon & \text { medium permittivity }[\mathrm{F} / \mathrm{m}] \\ \varepsilon_{\text {bulk }} & \text { dielectric constant in the bulk [-] } \\ \varepsilon_{\text {pore }} & \text { dielectric constant within the pore }[-] \\ \varepsilon_{0} & \text { vacuum permittivity }\left[8.854 \times 10^{-12} \mathrm{~F} / \mathrm{m}\right] \\ \eta & \text { solution viscosity [Pa s] } \\ \eta_{\text {mix }} & \text { mixing efficiency of the spacer [-] } \\ \lambda & \text { ratio between the solute radius and the pore radius }[-] \\ \xi & \text { electric potential gradient at the bulk-membrane interface }[\mathrm{V}] \\ \Xi & \text { correction factor for the mass transfer coefficient }[-] \\ \rho_{\mathrm{W}} & \text { solvent density }\left[\mathrm{kg} / \mathrm{m}^{3}\right] \\ \Phi_{\mathrm{i}} & \text { steric coefficient }[-] \\ \Phi_{\mathrm{B}} & \text { Born solvation contribution for partitioning }[-] \\ \psi & \text { electric potential across the membrane }[\mathrm{V}]\end{array}$

\title{
Subscripts and superscripts
}

b

bm

feed

i

j

$\mathrm{m}$

out

$\mathrm{p}$

ret

$\mathrm{X}$ solution entering into the interval along the NF element

bulk-membrane interface (NF element)

solution entering into the element

ion index

index for the discretization along the NF membrane thickness

inside the NF membrane

outlet of the NF unit

NF permeate along the NF element

NF retentate along the element

index for the discretization along the NF membrane length

\section{Acronyms}

CAPEX

COD

DSPM-DE

FF

IEX

LBC

MED

NF

OPEX

TVC

\author{
Capital Expenditure [US\$/y] \\ Chemical Oxygen Demand \\ Donnan Steric Pore Model with Dielectric Exclusion \\ Forward Feed \\ Ion Exchange Resins \\ Levelized Brine Cost [US $\$ / \mathrm{m}^{3}$ ] \\ Multi-Effect Distillation \\ Nanofiltration \\ Operating Expenditure [US\$/y] \\ Thermo-vapor compressor
}




\section{REFERENCES}

[1] J. Dai, S. Wu, G. Han, J. Winberg, X. Xie, X. Wu, X. Song, B. Jia, W. Xue, and Q. Yang, "Water-energy nexus: A review of methods and tools for macro-assessment," Applied Energy, vol. 210, pp. 393-408, 2018.

[2] J. Gilron, "Water-energy nexus: matching sources and uses," Clean Technologies and Environmental Policy, vol. 16, pp. 1471-1479, 2014.

[3] S. D. Tsolas, M. N. Karim, and M. M. F. Hasa, "Optimization of water-energy nexus: A network representation-based graphical approach," Applied Energy, vol. 224, pp. 230$250,2018$.

[4] A. Owen, K. Scott, and J. Barrett, "Identifying critical supply chains and final products: An input-output approach to exploring the energy-water-food nexus," Applied Energy, vol. 210, pp. 632-642, 2018.

[5] A. Dubreuil, E. Assoumou, S. Bouckaert, S. Selosse, and N. Maizi, "Water modeling in an energy optimization framework - The water-scarce middle east context," Applied Energy, vol. 101, pp. 268-279, 2013.

[6] B. Gjorgiev and G. Sansavini, "Electrical power generation under policy constrained water-energy nexus," Applied Energy, vol. 210, pp. 568-579, 2018.

[7] U. Lee, J. Han, A. Elgowainy, and M. Wang, "Regional water consumption for hydro and thermal electricity generation in the United States," Applied Energy, vol. 210, pp. 661672, 2018.

[8] B. Gjorgiev and G. Sansavini, "Water-energy nexus: Impact on electrical energy conversion and mitigation by smart water resources management," Energy Conversion and Management, vol. 148, pp. 1114-1126, 2017.

[9] M. Lee, A. A. Keller, P. C. Chiang, W. Den, H. Wang, C. H. Hou, J. Wu, X. Wang, and J. Yan, "Water-energy nexus for urban water systems: A comparative review on energy intensity and environmental impacts in relation to global water risks," Applied Energy, vol. 205, pp. 589-601, 2017.

[10] D. M. Warsinger, S. Chakraborty, E. W. Tow, M. H. Plumlee, C. Bellona, S. Loutatidou, L. Karimi, A. M. Mikelonis, A. Achilli, A. Ghassemi, L. P. Padhye, S. A. Snyder, S. Curcio, C. D. Vecitis, H. A. Arafat, and V. J.H. Lienhard, "A review of polymeric membranes and processes for potable water reuse," Progress in Polymer Science, vol. 81, pp. 209-237, 2018.

[11] D. Panepinto, S. Fiore, M. Zappone, G. Genon, and L. Meucci, "Evaluation of the energy efficiency of a large wastewater treatment plant in Italy," Applied Energy, vol. 161, pp. 404-411, 2016.

[12] D. Kirchem, M. Lynch, V. Bertsch, and E. Casey, "Market Effects of Industrial Demand Response and Flexibility Potential from Wastewater Treatment Facilities," 15th International Conference on the European Energy Market (EEM), pp. 1-6, 2018.

[13] S. Longo, B. M. d Antoni, M. Bongards, A. Chaparro, A. Cronrath, F. Fatone, J. M. Lema, M. Mauricio-Iglesias, A. Soares, and A. Hospido, "Monitoring and diagnosis of energy consumption in wastewater treatment plants. A state of the art and proposals for improvement," Applied Energy, vol. 179, pp. 1251-1268, 2016.

[14] D. Torregrossa, J. Hansen, F. Hernandez-Sancho, A. Cornelissen, G. Schutz, and U. Leopold, "A data-driven methodology to support pump performance analysis and energy efficiency optimization in Waste Water Treatment Plants," Applied Energy, vol. 208, pp. 1430-1440, 2017.

[15] Y. Gu, Y. Li, X. Li, H. P. amd Wang Luo, Z. P. Robinson, X. Wang, J. Wu, and F. Li, "The feasibility and challenges of energy self-sufficient wastewater treatment plants," Applied Energy, vol. 204, pp. 1463-1475, 2017. 
[16] E. Ahmetovic, N. Ibric, and Z. Kravanja, "Optimal design for heat-integrated water-using and wastewater treatment networks," Applied Energy, vol. 135, pp. 791-808, 2014.

[17] L. Yang and I. E. Grossmann, "Water Targeting Models for Simultaneous Flowsheet Optimization," Industrial and Engineering Chemistry Research, vol. 52, pp. 3209-3224, 2013.

[18] M. Molinos-Senante and R. Sala-Garrido, "Evaluation of energy performance of drinking water treatment plants: Use of energy intensity and energy efficiency metrics," Applied Energy, vol. 229, pp. 1095-1102, 2018.

[19] D. A. Roberts, E. L. Johnston, and N. A. Knott, "Impacts of desalination plant discharges on the marine environment: A critical review of published studies," Water Research, vol. 44, no. 18, pp. 5117-5128, 2010.

[20] A. Giwa, V. Dufour, F. A. Marzooqi, M. A. Kaabi, and S. W. Hasan, "Brine management methods: Recent innovations and current status," Desalination, vol. 407, pp. 1-23, 2017.

[21] S. Casas, C. Aladjem, E. Larrotcha, O. Gibert, C. Valderrama, and J. L. Cortina, "Valorisation of $\mathrm{Ca}$ and $\mathrm{Mg}$ by-products from mining and seawater desalination brines for water treatment applications," Journal of Chemical Technology and Biotechnology, vol. 89, pp. 872-883, 2014.

[22] J. M. Gozálvez-Zafrilla, D. Sanz-Escribano, J. Lora-García, and M. C. L. Hidalgo, "Nanofiltration of secondary effluent for wastewater reuse in the textile industry," Desalination, vol. 222, no. 1, pp. 272-279, 2008.

[23] L. Bilińska, M. Gmurek, and S. Ledakowicz, "Textile wastewater treatment by AOPs for brine reuse," Process Safety and Environmental Protection, vol. 109, pp. 420-428, 2017.

[24] J. K. Choe, A. M. Bergquist, S. Jeong, J. S. Guest, C. J. Werth, and T. J. Strathmann, "Performance and life cycle environmental benefits of recycling spent ion exchange brines by catalytic treatment of nitrate," Water Research, vol. 80, pp. 267-280, 2015.

[25] H. R. Flodman and B. I. Dvorak, "Brine Reuse in Ion-Exchange Softening: Salt Discharge, Hardness Leakage, and Capacity Tradeoffs," Water Environment Research, vol. 84, no. 6, pp. 535-543, 2012.

[26] J. Hu, Y. Chen, L. Guo, and X. Chen, "Chemical-free ion exchange and its application for desalination," Desalination, vol. 365, pp. 144-150, 2015.

[27] N. P. G. N. Chandrasekara and R. M. Pashley, "Study of a new process for the efficient regeneration of ion exchange resins," Desalination, vol. 357, pp. 131-139, 2015.

[28] J. Li, S. Koner, M. German, and A. K. SenGupta, "Aluminum-Cycle Ion Exchange Process for Hardness Removal: A New Approach for Sustainable Softening," Environmental Science and Technology, vol. 50, pp. 11943-11950, 2016.

[29] L. Birnhack, O. Keller, S. C. N. Tang, N. Fridman-Bishop, and O. Lahav, "A membranebased recycling process for minimizing environmental effects inflicted by ion-exchange softening applications," Separation and Purification Technology, vol. 223, pp. 24-30, 2019.

[30] Y. Chen, J. R. Davis, C. H. Nguyen, J. C. Baygents, and J. Farrell, "Electrochemical IonExchange Regeneration and Fluidized Bed Crystallization for Zero-Liquid-Discharge Water Softening," Environmental Science and Technology, vol. 50, pp. 5900-5907, 2016.

[31] www.zerobrine.eu, "Zero Brine."

[32] W. R. Bowen, A. W. Mohammad, and N. Hilal, "Characterisation of nanofiltration membranes for predictive purposes - use of salts, uncharged solutes and atomic force microscopy," Journal of Membrane Science, vol. 126, no. 1, pp. 91-105, 1997.

[33] W. R. Bowen and J. S. Welfoot, "Modelling the performance of membrane nanofiltration-critical assessment and model development," Chemical Engineering Science, vol. 57, no. 7, pp. 1121-1137, 2002.

[34] Filmtec Reverse Osmosis Membranes Technical Manual. . 
[35] A. W. Mohammad, N. Ali, A. L. Ahmad, and N. Hilal, "Optimized nanofiltration membranes: relevance to economic assessment and process performance," Desalination, vol. 165, pp. 243-250, 2004.

[36] U. K. Kesieme, N. Milne, H. Aral, C. Y. Cheng, and M. Duke, "Economic analysis of desalination technologies in the context of carbon pricing, and opportunities for membrane distillation," Desalination, vol. 323, pp. 66-74, 2013.

[37] A. W. Mohammad, N. Hilal, H. Al-Zoubib, N. A. Darwish, and N. Ali, "Modelling the effects of nanofiltration membrane properties on system cost assessment for desalination applications," Desalination, vol. 206, no. 1, pp. 215-225, 2007.

[38] B. Van der Bruggen, K. Everaert, D. Wilms, and C. Vandecasteele, "Application of nanofiltration for removal of pesticides, nitrate and hardness from ground water: rejection properties and economic evaluation," Journal of Membrane Science, vol. 193, no. 2, pp. 239-248, 2001.

[39] H. T. El-Dessouki and H. M. Ettouney, Fundamentals of Salt Water Desalination. Elsevier, 2002.

[40] H. Sayyadi and A. Saffari, "Thermoeconomic optimization of multi effect distillation desalination systems," Applied Energy, vol. 87, pp. 1122-1133, 2010.

[41] H. El-Dessouky, I. Alatiqi, S. Bingulac, and H. Ettouney, "Steady-State Analysis of the Multiple Effect Evaporation Desalination Process," Chem. Eng. Technol., vol. 21, no. 5, pp. 437-451, 1998.

[42] R. Turton, R. C. Bailie, W. B. Whiting, J. A. Shaeiwitz, and D. Bhattacharyya, Analysis, Synthesis and Design of Chemical Processes. Prentice Hall, 2012.

[43] T. Laukemann, R. Baten, and T. Fichter, "MENA Regional Water Outlook, Phase II, Desalination using Renewable Energy," Fichtner and DLR, 2012.

[44] M. Papapetrou, G. Micale, G. Zaragoza, and G. Kosmadakis, "Assessment of methodologies and data used to calculate desalination costs," Desalination, vol. 419, pp. 8-19, 2017.

[45] O. Labban, T. H. Chong, and J. H. Lienhard, "Design and modeling of novel low-pressure nanofiltration hollow fiber modules for water softening and desalination pretreatment," Desalination, vol. 439, pp. 58-72, 2018.

[46] Y. Roy, D. M. Warsinger, and J. H. Lienhard, "Effect of temperature on ion transport in nanofiltration membranes: Diffusion, convection and electromigration," Desalination, vol. 420, pp. 241-257, 2017.

[47] J. Schaep, C. Vandecasteele, A. W. Mohammad, and W. R. Bowen, "Analysis of the Salt Retention of Nanofiltration Membranes Using the Donnan-Steric Partitioning Pore Model," Separation Science and Technology, vol. 34, no. 15, pp. 3009-3030, 1999.

[48] D. L. Oatley, L. Llenas, N. H. M. Aljohani, P. M. Williams, X. Martínez-Lladó, M. Rovira, and J. de Pablo, "Investigation of the dielectric properties of nanofiltration membranes," Desalination, vol. 315, pp. 100-106, 2013.

[49] M. Ernst, A. Bismarck, J. Springer, and M. Jekel, "Zeta-potential and rejection rates of a polyethersulfone nanofiltration membrane in single salt solutions," Journal of Membrane Science, vol. 165, pp. 251-259, 2000.

[50] S. Bandini, "Modelling the mechanism of charge formation in NF membranes: Theory and application," Journal of Membrane Science, vol. 264, pp. 75-86, 2005.

[51] Carolina Mazzoni, Luigi Bruni, and S. Bandini, "Nanofiltration: Role of the Electrolyte and pH on Desal DK Performances," Ind. Eng. Chem. Res., vol. 46, pp. 2254-2262, 2007.

[52] M. R. Teixera, M. J. Rosa, and M. Nyström, "The role of membrane charge on nanofiltration performance," Jornal of Membrane Science, vol. 265, pp. 160-166, 2005.

[53] J. Schaep, C. Vandecasteele, A. W. Mohammad, and W. R. Bowen, "Modelling the retention of ionic components for different nanofiltration membranes," Separation and Purification Technology, vol. 22-23, pp. 169-179, 2001. 
[54] D. Zhou, L. Zhu, Y. Fu, M. Zhu, and L. Xue, "Development of lower cost seawater desalination processes using nanofiltration technologies - A review," Desalination, vol. 376, pp. 109-116, 2015.

[55] A. A. Al-Hajouri, A. S. Al-Amoudi, and A. M. Farooque, "Long term experience in the operation of nanofiltration pretreatment unit for seawater desalination at SWCC SWRO plant," Desalination and Water Treatment, vol. 51, no. 7-9, pp. 1861-1873, 2013.

[56] L. Llenas, X. Martinez-Lladó, A. Yaroshchuk, M. Rovira, and J. Pablo, "Nanofiltration as pretreatment for scale prevention in seawater reverse osmosis desalination," Desalination and Water Treatment, vol. 36, pp. 310-318, 2011.

[57] M. Micari, M. Moser, A. Cipollina, B. Fuchs, B. Ortega-Delgado, A. Tamburini, and G. Micale, "Techno-economic Assessment of Multi-Effect Distillation process for the Treatment and Recycling of Ion Exchange Resin Spent Brines," Desalination, vol. 456, pp. 38-52, 2019.

[58] D. Vezzani and S. Bandini, "Donnan equilibrium and dielectric exclusion for characterization of nanofiltration membranes," Desalination, vol. 149, pp. 477-483, 2002.

[59] V. Geraldes and M. D. Afonso, "Generalized Mass-Transfer Correction Factor for Nanofiltration and Reverse Osmosis," AIChE Journal, vol. 52, pp. 3353-3362, 2006.

[60] S. Senthilmurugan, A. Ahluwalia, and S. K. Gupta, "Modeling of a spiral-wound module and estimation of model parameters using numerical techniques," Desalination, vol. 173, pp. 269-286, 2005.

[61] V. Geraldes and A. M. B. Alves, "Computer program for simulation of mass transport in nanofiltration membranes," Journal of Membrane Science, vol. 321, no. 2, pp. 172-182, 2008.

[62] Y. Roy, M. H. Sharqawy, and J. H. Lienhard, "Modeling of flat-sheet and spiral-wound nanofiltration configurations and its application in seawater nanofiltration," Journal of Membrane Science, vol. 493, pp. 360-372, 2015.

[63] D. L. Oatley, L. Llenas, R. Pérez, P. M. Williams, X. Martínez-Lladó, and M. Rovira, "Review of the dielectric properties of nanofiltration membranes and verification of the single oriented layer approximation," Advances in Colloid and Interface Science, vol. 173, pp. 1-11, 2012. 


\section{Appendix A}

\section{A.1 Low-scale: membrane model, discretization along the thickness (y axis)}

The mechanisms within the membranes are described via the Donnan Steric Pore Model with Dielectric Exclusion (DSPM-DE). The DSPME-DE model derives from the resolution of the extended Nernst-Plank equation along the thickness of the membrane: it takes into account the three different mechanisms of ion transport, i.e. convection, diffusion and electro-migration (Equation 1 in Table A1). Along the $\mathrm{y}$ axis, which corresponds to the thickness of the membrane, the membrane is discretized in a certain number of elements, taken equal to 50 in the present work on the basis of a preliminary sensitivity analysis (as shown in paragraph A.4). The index employed for the elements along the $y$ axis is ' $j$ ', while the index ' $i$ ' represents the different ionic species, as typically used in literature.

The main equations are reported in Table $A 1$, where $\mathrm{C}^{\mathrm{m}_{i, j}}, \mathrm{C}^{\mathrm{bm}}{ }_{\mathrm{i}}, \mathrm{C}_{\mathrm{i}}^{\mathrm{b}}$ and $\mathrm{C}_{\mathrm{i}}$ represent the concentration of the species $i$ in the $\mathrm{j}$-th interval within the membrane, at the bulk-membrane interface just before entering in the pore, in the bulk solution and in the permeate, respectively. $\mathrm{J}_{\mathrm{i}}$ and $\mathrm{J}_{\mathrm{v}}$ are the overall flux of the species $i$ and the solvent (water) convective flux across the membrane, respectively. In addition, $\psi$ represents the electric potential across the membrane, $\xi$ the electric potential gradient at the bulk-membrane interface, outside the electric double layer, and $\Delta \psi_{\mathrm{D}, \mathrm{bm}}$ and $\Delta \psi_{\mathrm{D}, \mathrm{pm}}$ represent the Donnan potential difference at the bulk-membrane interface and at the permeate-membrane interface, respectively. $\mathrm{K}_{\mathrm{i}, \mathrm{c}}$ and $\mathrm{k}_{\mathrm{i}, \mathrm{d}}$ are the hindered convective and diffusive mass transfer coefficients of the ions within the pore, depending on $\lambda_{\mathrm{i}}$, i.e. the ratio between the solute radius $\left(r_{i}\right)$ and the pore radius $\left(r_{p o r e}\right)$, defined in equations 2-3. $\mathrm{D}_{\mathrm{i}, \mathrm{p}}$ (equation 4) is the diffusivity of the species $i$ within the pore, which is corrected with respect to the diffusivity in the bulk via $\mathrm{k}_{\mathrm{i}, \mathrm{d}}$. Solving the system of equations reported in Table A1 provides the ion partitioning at the two membrane interfaces (equation 5 for the bulk-membrane interface and equation 6 for the permeate-membrane interface), which is determined by the Donnan equilibrium, the steric effect (evaluated via the coefficient $\Phi_{\mathrm{i}}$, calculated via equation 11) and the dielectric exclusion (estimated through the coefficient $\Phi_{\mathrm{B}, \mathrm{i}}$, i.e. the Born solvation contribution for partitioning, see equations 9-10). This last effect was widely investigated in literature, since it has a prominent role in the definition of the ion rejection [58], [63]. In the interface equilibrium, the concentrations are multiplied by the activity coefficient $\gamma$, to take into account the non-ideality of the solutions, estimated via the Davies equations (see equations 78). Other conditions which have to be fulfilled are the electro-neutrality on the bulk, on the permeate side and inside the membrane, where a fixed charge density $\mathrm{X}_{\mathrm{d}}$ is present (Equation $12,13,14$ respectively). Finally, the mass transfer resistance on the bulk side is taken into 
account to calculate the concentration of the ions on the bulk-membrane interface (just before entering into the pore). Therefore, the balance in equation 15 represents the solute flux from the bulk to the membrane and it is used to estimate the role of the concentration polarization. The mass transfer coefficient in the bulk, $\mathrm{k}_{\mathrm{c}, \mathrm{i}}^{\text {bulk }}$ depends on the flow regime and is estimated via the correlation developed for spiral wound membranes [60], reported in equation 17. According to equation $16, \mathrm{k}_{\mathrm{c}, \mathrm{i}}^{\text {bulk }}$ is obtained multiplying the mass transfer coefficient $\mathrm{k}_{\mathrm{c}, \mathrm{i}}^{\text {bulk }}$ by a factor depending on the permeation flux through the membrane [59]. The concentration polarization effect is neglected on the permeate side. The solvent flux $J_{v}$ through the membrane, defined in equation 18, is estimated via Hagen-Poiseuille relation. It depends on the membrane geometric parameters and on the net driving pressure, $\Delta \mathrm{P}$, which is given by the pressure difference between bulk and permeate channel minus the osmotic pressure $\Delta \Pi$, given by equation 19 .

Table A1. Equations of the implemented DSPM-DE model.

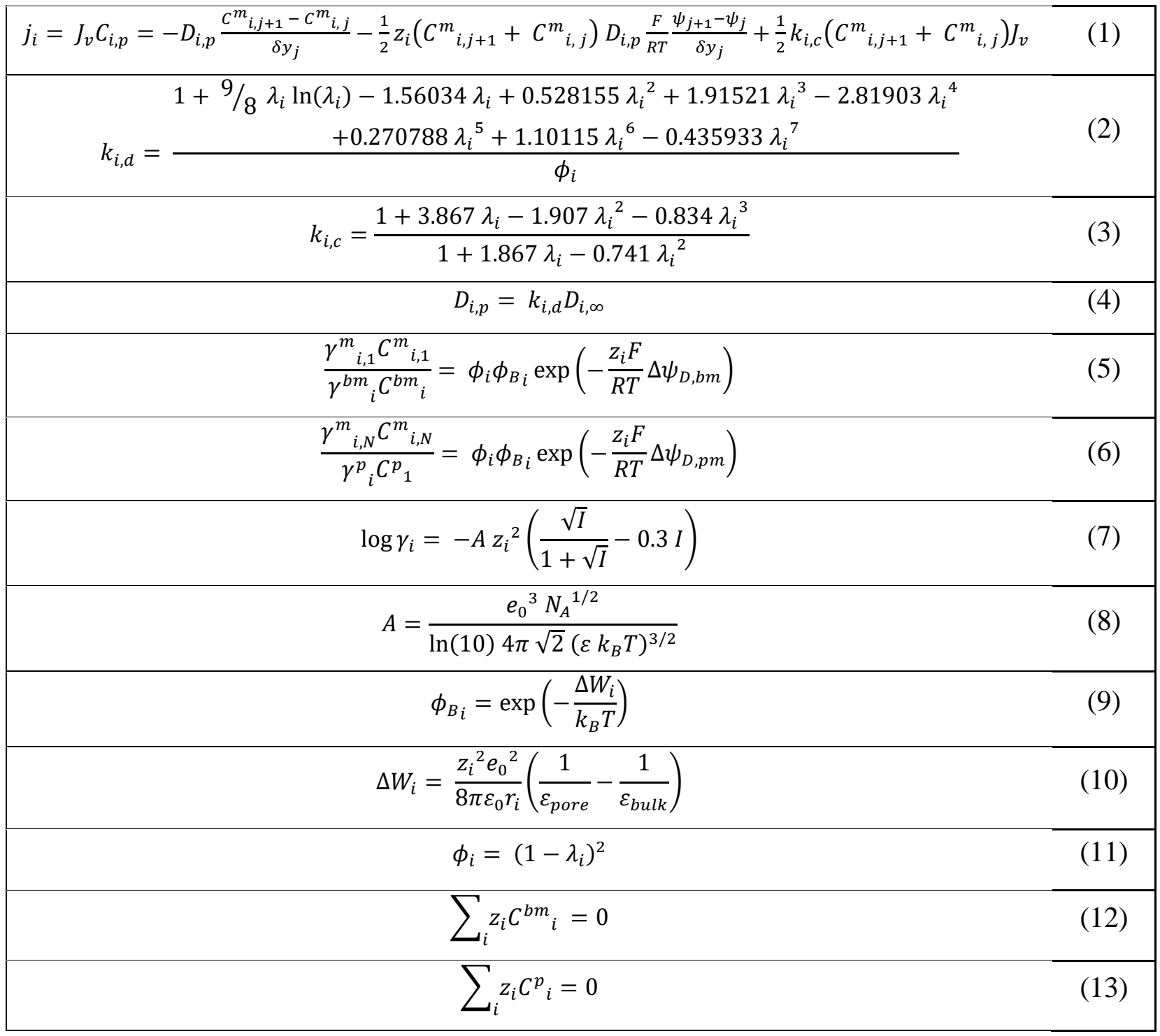




\begin{tabular}{|c|}
$\sum_{i} z_{i} C^{m_{i, j}}+X_{d}=0$ \\
\hline$j_{i}=-k_{c, i}^{\prime \text { bulk }}\left(C^{b m_{i}}-C^{b}{ }_{i}\right)+J_{v} C^{b m_{i}}-z_{i} C^{b m_{i} D_{i, \infty}} \frac{F}{R T} \xi$ \\
\hline$k_{c, i}^{\text {bulk }}=k_{c, i}^{\text {bulk }} \Xi=k_{c, i}^{\text {bulk }}\left[\frac{J_{v}}{k_{c, i}^{\text {bulk }}}+\left(1+0.26\left(\frac{J_{v}}{k_{c, i}^{\text {bulk }}}\right)^{1.4}\right)^{-1.7}\right]$ \\
\hline$k_{c, i}^{\text {bulk }}=0.753\left(\frac{\eta_{\text {mix }}}{2-\eta_{m i x}}\right)^{1 / 2}\left(\frac{D_{i, \infty}}{h_{f}}\right) S c^{-1 / 6}\left(\frac{P e_{i} h_{f}}{L_{m i x}}\right)^{1 / 2}$ \\
\hline$J_{v}=\frac{\Delta P r_{\text {pore }}{ }^{2}}{8 \eta \delta_{m}}$ \\
\hline$\Delta \Pi=R T \sum \sum_{i}\left(C^{b m_{i}}-C^{p}{ }_{i}\right)$ \\
\hline$P e=\frac{2 h_{f} u_{f}}{D_{i, \infty}}$ \\
\hline$S c=\frac{\eta_{f}}{\rho_{f} D_{i, \infty}}$
\end{tabular}

where $\eta_{\text {mix }}$ is the mixing efficiency of the net of the spacer [60], $h_{f}$ is the height of the feed channel, $\mathrm{L}_{\text {mix }}$ is the mixing length of the spacer, Pe and Sc are the Peclet and the Schmidt adimensional numbers respectively, defined in equation 20 and 21 , and where $u_{f}, \rho_{\mathrm{f}}$ and $\eta_{\mathrm{f}}$ are the feed solution velocity, density and viscosity respectively.

The system of equations composing the DSPM-DE model is linearized according to [61] and solved in Python via the LAPACK routine_gesv. The problem is then solved via iterations, updating the coefficients of the linearized equations and solving the linear system, until the residuals relevant to the imposed conditions are low enough $\left(<10^{-4}\right)$.

\section{A.2 Middle-scale: element model, discretization along the length ( $\mathrm{x}$ axis)}

At the middle scale, the low scale model is integrated for the resolution of a whole NF element. In the present middle-scale model, an iterative calculation is set up, where the average values of the concentration, flow rates and pressure are firstly guessed in each discretization interval (x-th interval) for the calculation of the osmotic pressure and the bulk mass transfer coefficient, thus the low-scale model is applied to calculate the ions rejection and the water flux. Finally, the outlet concentrations and flow rates for each discretization interval are calculated via mass balances, as reported in Table A2. The pressure losses along the element are defined according to [62].

Table A2. Equations to model a nanofiltration element. 


\begin{tabular}{|c|c|}
\hline$M_{p_{x}}=M_{p_{x-1}}+J_{v_{x}} \frac{A_{\text {membr }, \text { elem }}}{n_{\text {discr }, L}}$ & $(22)$ \\
\hline$M_{\text {ret }_{x}}=M_{b_{x}}-J_{v_{x}} \frac{A_{\text {membr }, \text { elem }}}{n_{\text {discr }, L}}$ & $(23)$ \\
\hline$C^{p}{ }_{i_{x}}=\frac{C^{p_{i_{x-1}}} M_{p_{x-1}}+j_{i_{x}} \frac{A_{\text {membr }, \text { elem }}}{n_{\text {discr }, L}}}{M_{p_{x}}}$ & $(24)$ \\
\hline 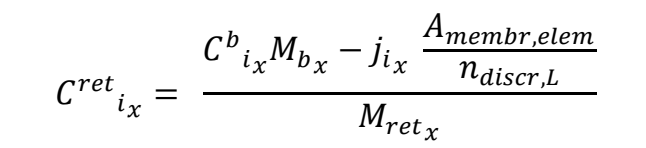 & $(25)$ \\
\hline$M_{b_{x}}=M_{\text {ret }_{x-1}}$ & $(26)$ \\
\hline$C^{b}{ }_{i_{x}}=C^{r e t}{ }_{i_{x-1}}$ & $(27)$ \\
\hline$P_{x}=P_{x-1}-\Delta P_{\text {losses }}=P_{x-1}-\frac{f}{2} \frac{l}{D_{H}} \varrho_{f} u_{f}^{2}$ & $(28)$ \\
\hline$f=\frac{6.23}{R e^{0.3}}$ & (29) \\
\hline$R e=\frac{\rho_{f} u_{f} D_{H}}{\eta_{f}}$ & $(30)$ \\
\hline
\end{tabular}

where $\mathrm{M}_{\mathrm{p}}$ and $\mathrm{C}_{\mathrm{i}}$ are the mass flow rate and the concentrations in the permeate channel, $\mathrm{M}_{\text {ret }}$ and $\mathrm{C}^{\mathrm{ret}}{ }_{\mathrm{i}}$ are the flow rate and the concentrations in the retentate channel, which are equal to the feed flow rate and the concentration of the feed in the next interval $\left(\mathrm{M}_{\mathrm{b}}\right.$ and $\left.\mathrm{C}_{\mathrm{i}}^{\mathrm{b}}\right)$, and $\mathrm{A}_{\text {membrelem }}$ and $\mathrm{n}_{\text {discr,L }}$ are the total membrane area of a NF element and the number of discretization intervals along the main feed flow direction. Regarding the pressure losses definition, $\mathrm{f}$ is the friction factor, 1 is the length of the discretization interval and $D_{H}$ is the hydraulic diameter relevant to the feed channel, employed also in the calculation of the Reynolds number Re, defined in equation 30 .

\section{A.3 High-scale: plant model, vessels arrangement}

The high scale model is devoted to calculating the total number of vessels required for the achievement of a certain recovery. In the model, an iterative calculation is performed to estimate the total membrane area required to achieve a certain recovery rate. Firstly, a guess number of vessels in parallel (i.e. a guess total membrane area) is given through the ratio between the required permeate flow rate and a guessed average water flow rate through the membrane $\left(J_{\mathrm{v}}\right)$. On the basis of the number of vessels in parallel, the feed flow rate for each vessel is calculated and the series of elements within the single vessel is solved. Then, the average solvent flux in the vessel is recalculated in relation to the net driving pressure along the elements, and the total recovery rate is calculated. At this point, the number of pressure vessels in parallel is updated 
assuming a linear correlation between the number of vessels and the recovery and another iteration starts. The iterative calculation stops as soon as the overall recovery ratio is higher than or equal to the required one. This last iterative procedure is of crucial importance, since the solvent flux through the membrane changes significantly within one element and along the vessel. As a matter of fact, assuming an average flux equal to the one at the first element entrance may lead to a strong underestimation of the required number of vessels, which would have important economic consequences.

\section{A.4 Membrane-scale model validation and sensitivity analysis}

As mentioned in paragraph A.1, the membrane thickness has been discretized in 50 elements. The discretization has been selected as the result of a sensitivity analysis, where the number of steps was varied from 10 to 100 . Figure A. 1 shows the trends of the concentration of $\mathrm{Ca}^{2+}$ and $\mathrm{Mg}^{2+}$ throughout the membrane thickness at different numbers of discretization steps. Notably, the trends are overlapped for $\mathrm{N}$ higher than or equal to 50 . Therefore, it is possible to conclude that a 50-steps discretization is able to predict accurately the behaviour of the NF membrane.

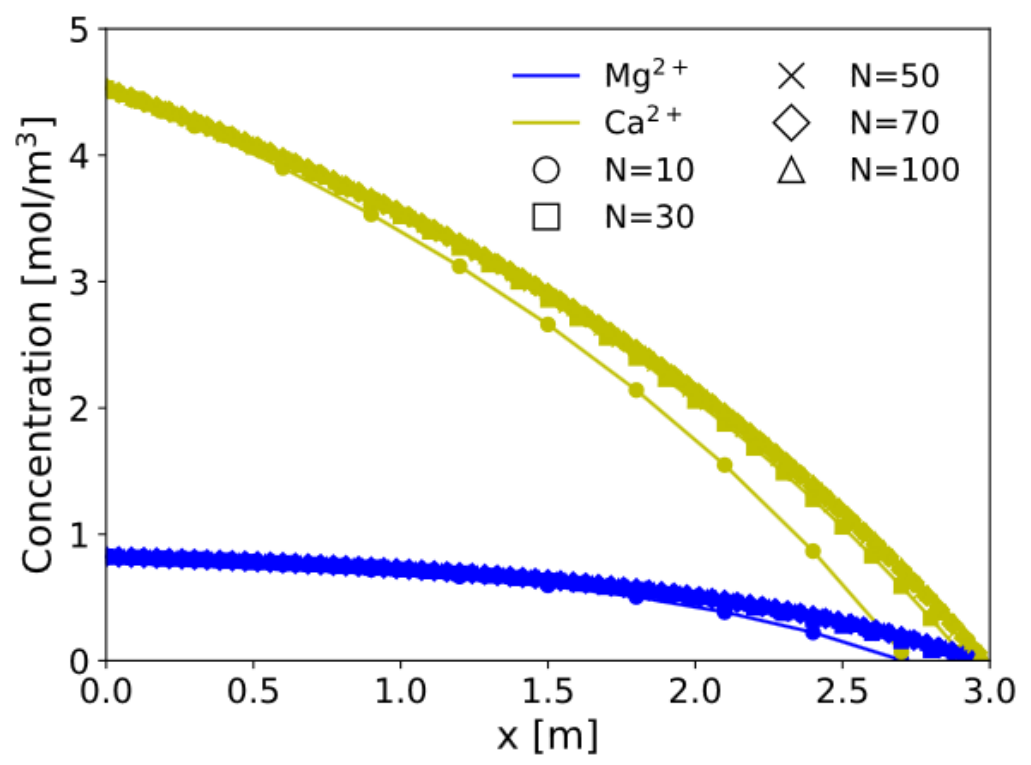

Figure A. 1 Sensitivity analysis results: trend of the concentration of $\mathrm{Mg}^{2+}$ and $\mathrm{Ca}^{2+}$ throughout the membrane thickness varying the number of discretization steps.

Finally, the implemented DSPM-DE model was validated via the comparison with some experimental results reported in literature for two different salt solutions in presence of NF270 membranes [63]. For this case, we adopted the same membrane parameters reported in the 
reference work. As shown in Figure A. 2, there is a very good agreement between the experimental and the model results for both cases.

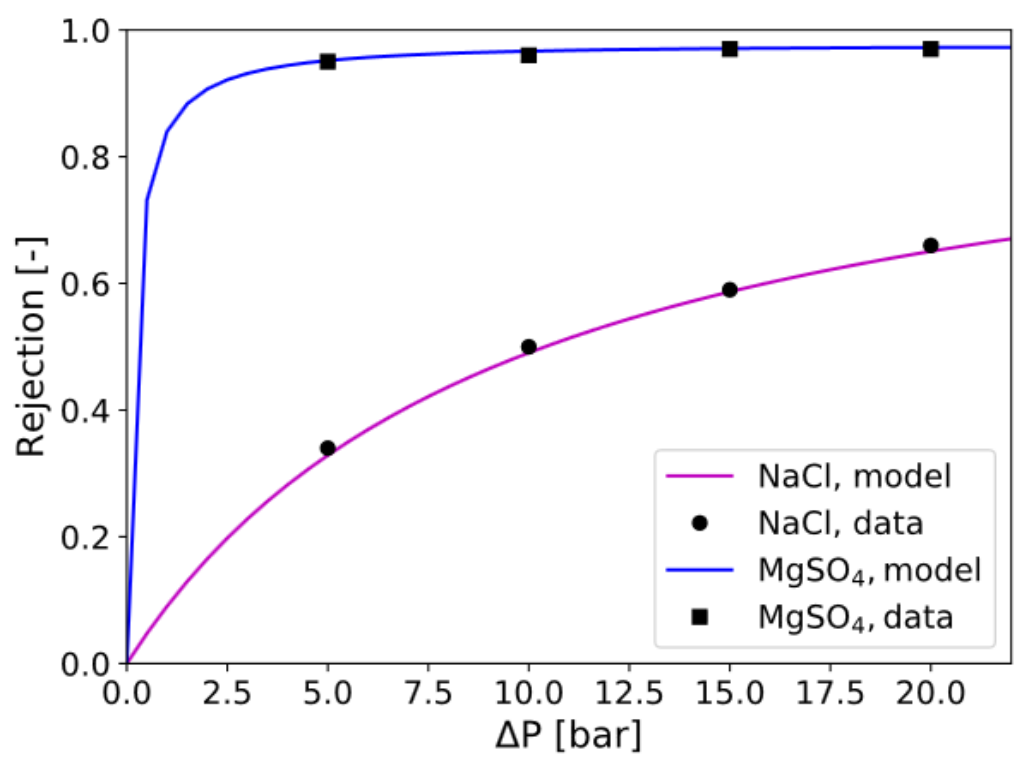

Figure A. 2 Experimental values of ions' rejection and trends simulated by the model in presence of $\mathrm{NaCl}$ or $\mathrm{MgSO}_{4}$ solutions with $\mathrm{NF} 270$ membranes. 